\title{
ACCEPTED MANUSCRIPT \\ Towards the Generalization of Membrane Structure-Property Relationship of Polyimides and Copolyimides: A Group Contribution Study
}

\author{
Sadiye Velioğlu ${ }^{\mathrm{a}}$, S. Birgül Tantekin-Ersolmaz ${ }^{\mathrm{b}}, \mathrm{Jia}_{\mathrm{Wei}} \mathrm{Chew}^{\mathrm{a}, \mathrm{c}, *}$ \\ a. School of Chemical and Biomedical Engineering, Nanyang Technological University, Singapore, \\ 637459, Singapore \\ b. Istanbul Technical University, Dept. of Chemical Engineering, Maslak 34469, Istanbul, Turkey \\ c. Singapore Membrane Technology Centre, Nanyang Environment and Water Research Institute, \\ Nanyang Technological University, Singapore 637141, Singapore \\ *Corresponding author, e-mail: jchew@ntu.edu.sg
}

\begin{abstract}
While polymeric membranes are conventional for gas separation processes, significant improvements remain possible and thereby the search for novel polymers is still on-going. The present study provides a way to develop structure-property relationship for polyimides and copolyimides, in order to lead new experimental studies with respect to recommendations on tunable monomers with promising transport properties for specific applications. This method advances the group contribution study based on molar volume contributions of subunits proposed by Robeson et al. [1] for the prediction of $\mathrm{He}, \mathrm{H}_{2}, \mathrm{O}_{2}, \mathrm{~N}_{2}, \mathrm{CO}_{2}$ and $\mathrm{CH}_{4}$ permeability parameters and $\mathrm{O}_{2} / \mathrm{N}_{2}, \mathrm{CO}_{2} / \mathrm{CH}_{4}, \mathrm{H}_{2} / \mathrm{CO}_{2}$, $\mathrm{H}_{2} / \mathrm{CH}_{4}, \mathrm{CO}_{2} / \mathrm{N}_{2}$, and $\mathrm{He} / \mathrm{N}_{2}$ perm-selectivities of 490 polyimide and copolyimide structures. The database is screened to identify the high-performing subunits among the 107 considered, then the defined permeability contributions and volume ratios of such subunits are used to predict the gas separation performance (i.e., selectivity and permeability) of the resulting copolyimides. Firstly, the results indicate enhanced agreement between experimental and predicted transport properties, presumably due to the division of the polymer structure into large subunits, the definition of volume quantities of subunits, the expanded database and the consideration of a specific polymer class (namely, polyimides and copolyimides). Secondly, the $\mathrm{CO}_{2} / \mathrm{N}_{2}$ and $\mathrm{He} / \mathrm{N}_{2}$ gas separation properties cannot be further improved beyond the selectivity-permeability trade-off bound even with a judicious coupling of high-performing subunits, but separations of other gas pairs can exceed the existing upper bound by the incorporation of subunits with sulphone or side methyl groups, used as precursors of thermally rearranged polymers, or with spiro-centered or bridged bicyclic features. One of the key contributions of this study is the recommendation for the synthesis of the polymers
\end{abstract}


represented by the predicted data points above the trade-off bounds to further enhance gas separations.

Keywords: Membrane-based gas separation; Copolyimide; Permeability and selectivity; Volumebased group contribution method; Structure-property relationship. 


\section{Introduction}

\section{ACCEPTED MANUSCRIPT}

Due to the advantages of membrane-based separation processes such as lower capital, operation and maintenance costs, smaller environmental footprint and ease of process integration compared to the traditional separation techniques, there is growing interests in the membrane-based purification of commercially relevant gases. However, at present, material performance is a key bottleneck, limiting the widespread implementation of membrane processes for gas separation in the industry [2-7]. Therefore, in the last decade, efforts dedicated towards developing superior polymeric membranes that enable high permeability and selectivity, as well as good mechanical and thermal resistance, have escalated. Unfortunately, customizing all these interconnected and occasionally counteracting properties simultaneously is incredibly challenging and time-consuming experimentally, which necessitates tools that allows for the determination of structure-property relationships and enables rapid screening of a large number of polymeric structures.

Polyimides, and the associated high-performance aromatic polymers, have emerged as prominent membrane materials for industrial gas separation processes [7-9]. Such polymers are superior to other polymers for three primary reasons: (i) exhibit structural rigidity and high glass transition temperature, hence offer desirable physical properties under the typical operation conditions of membrane separation processes; (ii) high separation performance approaching towards the upper limit of the permeability-selectivity trade-off relationships for many gas pairs; and (iii) it is possible to modify the performance of such polymers by engineering slight modifications in their chemical structures. Regarding (iii), unfortunately, a small chemical change may result in significant, often unexpected, and not necessarily advantageous alterations. For instance, polyimides constituted from the 6FDA dianhydride and pDiMPD, mTrMPD and pTeMPD diamines display carbon dioxide $\left(\mathrm{CO}_{2}\right)$ permeability of approximately 40, 550 and 450 Barrer, respectively [10-14], which clearly indicates the sensitivity of the performance to the constituent groups. In particular, the only difference leading to the order-of-magnitude difference in permeability is merely the number of methyl side groups attached to the benzene ring in the diamine structure. Correspondingly, the development of structureproperty relationships for polyimides is crucial to enable the ability to predict permeability and selectivity from polymeric structural units, and provide guidelines for designing optimized membrane candidates with desirable end-use properties. Towards this end, the group contribution method has become a prominent tool for the fast screening of possible compositions, especially in the design of novel polyimides or monomers, or the selection of the continuous phase for mixedmatrix membranes [1, 15-19]. The relationship between the parameters adopted in the method and 
ACCEPTED MANUSCRIPT

the separation properties of the resulting polymeric membrane is of great interest towards the aim of enhancing predictive capability.

Copolyimides allows for the optimization of the separation properties by the coupling of two different polyimides with different permeability and selectivity properties. This provides an opportunity for the synthesis of novel polymers with desired properties. Considering the structural complexity of the copolyimides, the experimental analysis of the separation properties of all the copolyimide structures to identify the best one is a tedious and time-consuming task. Fortunately, using the group contribution method, hundreds of different copolyimide structures made up by combining monomers that have not been coupled before can be evaluated to identify suitable pairs that can exceed the selectivity-permeability trade-off bound for different gas separations. Considerable progress has been made in the modeling of the transport properties of glassy polymers of various structures since the first in 1986 [20]. A well-established approach was set up by Robeson et al. [1, 18] for permeability predictions of aromatic polymers based on the molar volume (instead of empirical factors [15]) as a normalization parameter and the permeability contribution of each subunit. Subsequently, Alentiev et al. [16] proposed the use of larger subunits and molar fraction (rather than molar volume) that reduced the error in the predictions for polyimides. Velioglu and Tantekin-Ersolmaz [17] extended the method of Alentiev et al. [16] to copolyimides and further improved on the accuracy by accounting for the ratio between the pairs of dianhydride or diamine. Later, Ryzhikh et al. [19] used the bond contribution method for permeability and diffusivity predictions using a large database of polymers, obtaining more accurate predictions than their earlier work based on modified atomic contributions. Although group contribution predictions for a range of polymer types has been reported, a focus on polyimides and copolyimides is needed in view of the prominent applications in gas separations. Accordingly, based on the group contribution method, the present study attempts to screen through monomers available in literature to identify the highperforming ones, then combine them into new copolyimides with potentially superior separation properties. This would provide insights towards the understanding and also synthesis of new structures to enhance gas separation.

In this study, we focus on advancing the development of the incremental group contribution method of Robeson et al. [1] for the prediction of the gas transport parameters of polyimides and copolyimides. Specifically, the group contribution method of Robeson et al. [1] is revisited using a much enlarged set of structures with larger sub-units (dianhydrides and diamines) to predict the permeability of helium $(\mathrm{He})$, hydrogen $\left(\mathrm{H}_{2}\right)$, oxygen $\left(\mathrm{O}_{2}\right)$, nitrogen $\left(\mathrm{N}_{2}\right)$, carbon dioxide $\left(\mathrm{CO}_{2}\right)$ and methane $\left(\mathrm{CH}_{4}\right)$, and the selectivity of gas pairs $\mathrm{O}_{2} / \mathrm{N}_{2}, \mathrm{CO}_{2} / \mathrm{CH}_{4}, \mathrm{H}_{2} / \mathrm{CO}_{2}, \mathrm{H}_{2} / \mathrm{CH}_{4}, \mathrm{CO}_{2} / \mathrm{N}_{2}$, and 
$\mathrm{He} / \mathrm{N}_{2}$. The objective is twofold: (i) prove the applicability and the effectiveness of this new approach in getting the representative parameters for dianhydrides and diamines; and (ii) assess the possibility of exceeding the upper bound limit based on the trade-off between selectivity and permeability via the judicious choice of monomer combinations. In doing this, we will take advantage of molecular simulations in the calculation of molar volumes of the subunits.

\section{Group Contribution Method}

The group contribution studies differ insofar as whether they consider van der Waals volume or molecular mass of the elements in the parameter predictions. Group contribution methods are generated based on three assumptions. Firstly, the structure of the polymer is divided into several representative subunits that collectively yield the property of the polymer. Secondly, the properties of the subunits are presumed constant for all polymeric structures. Finally, the polymeric properties are accounted for as a sum of the corresponding subunits factored with the adopted weight factors, such as, volume, molar, etc. [2].

The development of efficacious methods for predicting the transport properties of polymeric membranes is of paramount importance to facilitate the development of high-performance membranes. The group contribution method proposed by Robeson et al. [1, 18] for several types of aromatic polymers is one such method which enables quick screenings of a large number of polymer structures. In this study, the group contribution is applied specifically for polyimide and copolyimide membranes.

\subsection{Preliminary preparation}

We utilize the database available on the website of the Membrane Society of Australasia [21] for polymeric gas separation membranes, and also include recent literature that identifies newly synthesized polyimides. All 490 polyimide and copolyimide structures available are used for the predictions. Three notes are worth indicating. Firstly, to ensure data reliability and compatibility, pure gas permeability data obtained above $10 \mathrm{~atm}$ are filtered out specifically for carbon dioxide $\left(\mathrm{CO}_{2}\right)$ measurements because the plasticization effect at high pressure is known to increase permeability and decrease selectivity by promoting inter-segmental mobility and fractional free volume (FFV). Secondly, while the compiled database contains primarily the permeability coefficients of polymers measured at $35{ }^{\circ} \mathrm{C}$, minor corrections are made for sources at different temperatures using available correlations for activation energies of glassy polymers [1, 22]. Thirdly, 
ACCEPTED MANUSCRIPT

other classifications associated with the solvent type used in the film preparation, residual solvent amount and membrane preparation are not factored into the data compilation.

The subdivision of the repeat unit of the polymer into subunits or fragments is a basic principle in the group contribution methods. Contrary to the study of Robeson et al. [1] which used short subunits, diamine and dianhydride are proposed as subunits in this study per that in Alentiev et al. [16]. So, each repeat unit of the polyimide is represented by two subunits, namely, a dianhydride and a diamine. Notably, while short subunits may be beneficial in the extrapolation of the method to represent different classes of polymeric structures whose data have not been used in the prediction, greater discrepancies can be expected when expanding the applicability domain. Larger subunits such as dianhydride and diamine, as per the study of Alentiev et al. [16], address this shortcoming, since the chemical bonds are more accurately accounted for in the assembly of the polymer.

\subsection{Volume calculation via molecular simulation}

The group contribution method of Robeson et al. [1] is revisited using an enlarged set of polymeric structures with a total of 107 subunits (i.e., 32 dianhydrides and 75 diamines). Table 1 lists all 107 subunits, along with the chemical structures, van der Waals volumes, and the gas permeability contributions for $\mathrm{He}, \mathrm{H}_{2}, \mathrm{O}_{2}, \mathrm{~N}_{2}, \mathrm{CO}_{2}$ and $\mathrm{CH}_{4}$. Advances in molecular modeling provide the opportunity to more accurately calculate the thermodynamic properties of the species. In order to define the values of volume fraction $\left(\phi_{\mathrm{i}}\right)$, molecular simulation tools are used to predict molar volume of contributions. Molecular dynamic simulations are carried out using Large-scale Atomic/Molecular Massively Parallel Simulator (LAMMPS) [23]. The minimized subunits are subjected to short runs using isobaric-isothermal ensemble at 1 bar and $35{ }^{\circ} \mathrm{C}$ for equilibration whereby all molecular interactions are modeled with the cvff force field [24]. Temperature and pressure are maintained to the targeted value by the Nosé-Hoover thermostat and barostat with a coupling time constant of 100 and $500 \mathrm{fs}$, respectively. The simulation time step is set to $1 \mathrm{fs}$. Once the detailed atomistic model of the subunits is constructed, the van der Waals volumes via the Connolly task simulation are calculated directly using the Atom Volumes \& Surfaces tool in Discovery Studio 2016 [25], instead of using the Bondi method [26]. Therefore, by using large subunits, all possible atomic interactions in the neighborhood of the monomer are included and thereby highly reliable configurations of the subunits are obtained for a better representation of the subunit volume. 


\subsection{Matrix preparation and solver}

\section{ACCEPTED MANUSCRIPT}

In order to find the permeability contribution of the 107 subunits (i.e., 32 dianhydrides and 75 diamines), whose structures are depicted in Table 1, we first construct a matrix. Notably, while some combinations that can be derived from the present subunits do not have corresponding polyimides reported in the literature, some dianhydrides have been repeatedly used in the preparation of polyimides. The different permeability results reported by several authors for the same polyimide are also included as an extra row into the matrix of the system.

To obtain a set of linear equations in which every row corresponds to a certain polyimide or copolyimide, an explicit form of the equation proposed by Robeson et al. [1] (Eq. 1) is expanded as Eq. 2.

$$
\begin{aligned}
& \ln \mathrm{P}=\sum_{\mathrm{i}=1}^{\mathrm{n}} \phi_{\mathrm{i}} \ln \mathrm{P}_{\mathrm{i}} \\
& \ln \mathrm{P}_{\mathrm{m}}=\phi_{1} \ln \mathrm{M}_{1 \mathrm{~m}}+\phi_{2} \ln \mathrm{M}_{2 \mathrm{~m}}+\ldots+\phi_{\mathrm{n}} \ln \mathrm{M}_{\mathrm{nm}}+\phi_{\mathrm{n}+1} \ln \mathrm{N}_{1 \mathrm{~m}}+\phi_{\mathrm{n}+2} \ln \mathrm{N}_{2 \mathrm{~m}}+\ldots+\phi_{\mathrm{n}+\mathrm{k}} \ln \mathrm{N}_{\mathrm{km}}
\end{aligned}
$$

In Eq. 2, $\mathrm{M}$ and $\mathrm{N}$ correspond to the specific contributions of the dianhydrides and diamines, respectively; the subscripts $\mathrm{n}$ and $\mathrm{k}$ represent numbers of dianhydride and diamine used to constitute a polyimide and/or copolyimide, respectively; and $\mathrm{P}, \mathrm{m}$, and $\phi$ stand for permeability of a polymer, investigated gas type, and molar volume ratio of subunit. The matrix which involves the set of linear equations is solved by least square fit with the QR solver in Matlab. Specifically, the QR solver is used to find the minimum-norm-residual solution to the linear system $A x=B$, which can be overdetermined as in our case. For each gas (defined as $\mathrm{m}$ in Eq. 7), such as $\mathrm{He}, \mathrm{H}_{2}, \mathrm{O}_{2}, \mathrm{~N}_{2}, \mathrm{CO}_{2}$ and $\mathrm{CH}_{4}$, a new matrix is established to calculate the permeability contributions of each subunit in order to define the polyimide property for every gas. This enables the updating of the polyimide structures in the database established in 2000 [16] as new data for some gases become available for new subunits.

\subsection{Proposal of new copolyimides}

Following the calculation of the specific contributions of subunits, comparison in terms of the selectivity-permeability plots for $\mathrm{O}_{2} / \mathrm{N}_{2}, \mathrm{CO}_{2} / \mathrm{CH}_{4}, \mathrm{H}_{2} / \mathrm{CO}_{2}, \mathrm{H}_{2} / \mathrm{N}_{2}$, and $\mathrm{CO}_{2} / \mathrm{N}_{2}$ separation applications is made. This allows for the identification of the most outstanding diamine and dianhydrides with the best permeability/perm-selectivity values for each gas separation application, and thereby new and better copolyimide structures are proposed for each gas pair. The dianhydride:dianhydride or diamine:diamine ratios are set as 50:50. Permeability-selectivity plots 
with upper bounds established in 1991 and 2008 based on the trade-off between permeability and selectivity defined by Robeson [27, 28] are introduced to show the performance of the proposed copolyimide structures and elucidate the limitations for each gas separation.

\section{Results and Discussion}

\subsection{Production of data set for subunits and error analysis}

The comparison between experimental and predicted gas permeability coefficients for $\mathrm{He}, \mathrm{H}_{2}, \mathrm{O}_{2}$, $\mathrm{N}_{2}, \mathrm{CO}_{2}$ and $\mathrm{CH}_{4}$ for the polyimides and copolyimides made up of 107 subunits is depicted in Figure 1, which are logarithmic plots of experimental versus predicted values. The dashed lines represent one-quarter $( \pm 0.25)$, one-half $( \pm 0.5)$ and one $( \pm 1.0)$ order-of-magnitude of deviations between the predicted and experimental data. Note that one order-of-magnitude implies that the predicted value is ten times greater $(+)$ or smaller (-) than the experimental value. Figure 1 shows that experimental and predicted permeability values agree very well to largely within a quarter of an order-ofmagnitude, which is significantly lower than the half an order-of-magnitude of discrepancy by Alentiev et al. [16], and thereby underscores the improved predictions by the volume-based approach with large subunits used here. Notably, the recent group contribution study by Alentiev et al. [19] shows that the discrepancy is more than one order-of-magnitude, presumably due to the consideration of a large number of polymers (namely, 900), and also different types of polymer structures (such as polyimides, polyacetylenes, polyesters, polyetheres, polysulfons, etc). 


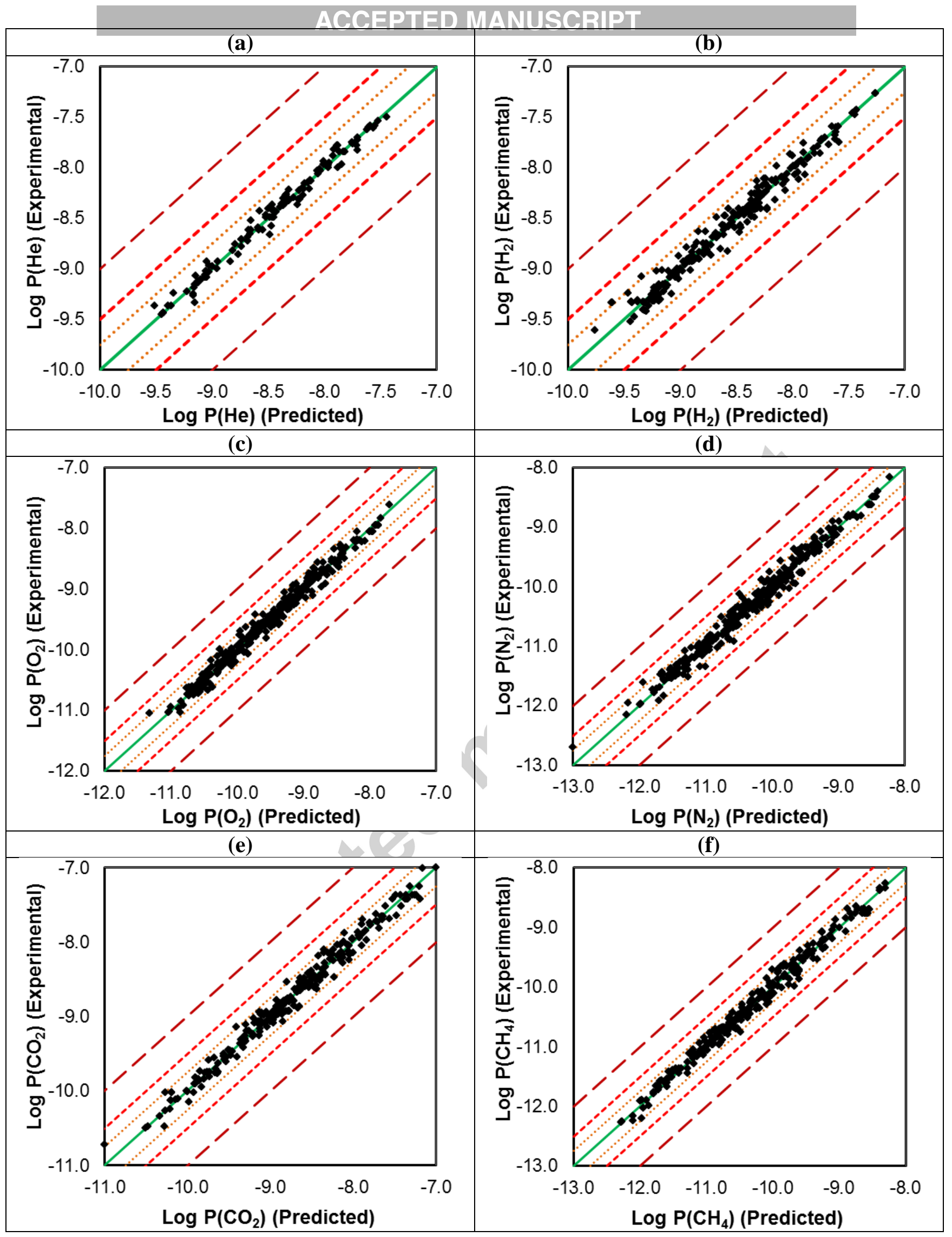

Figure 1. Comparison of experimental and predicted permeability coefficients calculated from the subunit contributions defined here for (a) $\mathrm{He}$, (b) $\mathrm{H}_{2}$, (c) $\mathrm{O}_{2}$, (d) $\mathrm{N}_{2}$, (e) $\mathrm{CO}_{2}$, and (f) $\mathrm{CH}_{4}$. (Figure displays the lower left quadrant of the Cartesian coordinate system) 
Table 2. Error analysis of the permeability coefficients calculated by the proposed method in this study as well as other methods whose error analyses are available.

\begin{tabular}{|c|c|c|c|c|c|c|c|}
\hline$\sigma{\text { (standard deviation })^{\mathrm{a}}}^{\mathrm{a}}$ & 0.14 & 0.26 & 0.30 & 0.29 & 0.24 & 0.23 & \multirow{3}{*}{ This study } \\
\hline $\mathrm{E}(\text { average error } \%)^{\mathrm{b}}$ & 9.22 & 17.2 & 20.9 & 21.2 & 16.9 & 17.4 & \\
\hline Number of polymers & 115 & 235 & 345 & 337 & 324 & 268 & \\
\hline$\sigma^{\mathrm{a}}$ & 0.11 & -- & 0.18 & 0.21 & 0.22 & 0.25 & \multirow{3}{*}{$\begin{array}{l}\text { Robeson et } \\
\text { al. }[1,18]\end{array}$} \\
\hline$E^{b}$ & --- & --- & --- & --- & 17.3 & 19.9 & \\
\hline Number of polymers & 65 & --- & 65 & 65 & 87 & 87 & \\
\hline$E^{b}$ & 21.6 & 26.1 & 37.3 & 34.8 & 38.7 & 39.1 & \multirow{2}{*}{$\begin{array}{l}\text { Park and } \\
\text { Paul [15] }\end{array}$} \\
\hline Number of polymers & 79 & 63 & 102 & 101 & 101 & 102 & \\
\hline
\end{tabular}

Table 2 further quantifies statistically the error associated with the permeability coefficients for the gases investigated (namely, $\mathrm{He}, \mathrm{H}_{2}, \mathrm{O}_{2}, \mathrm{~N}_{2}, \mathrm{CO}_{2}$ and $\mathrm{CH}_{4}$ ) in terms of standard deviation $(\sigma)$ and average percent relative error (E); the statistics are presented for the method used here as well as that by others $[1,15,18]$ whose error analyses are available. Two observations warrants highlighting. Firstly, Park and Paul [15] gives significantly higher E values despite the molar volume based approach, which is presumably because of the wide variety of polymers (such as polysulfones and polycarbonates) considered. This underscores the dominance of other parameters in the calculation protocol (e.g., definition of molar volume and subunits) in the accuracy of the predictions for the group contribution method. Secondly, the $\sigma$ and $\mathrm{E}$ values for the current method are similar to those by Robeson et al. [1, 18], in spite of a much larger number of polymers considered in this study, which affirms the reliability of the subunit contribution derived by this method.

Addressing the risk of error escalation in predictions of selectivity between gas pairs is among the most important challenges, since the ideal selectivity is calculated as the ratio of the permeability coefficients. Accordingly, the comparisons between the experimental and predicted ideal selectivity values, calculated from the ratio of the permeability coefficients, for the gas pairs of $\mathrm{O}_{2} / \mathrm{N}_{2}$, $\mathrm{CO}_{2} / \mathrm{CH}_{4}, \mathrm{H}_{2} / \mathrm{CO}_{2}, \mathrm{CO}_{2} / \mathrm{N}_{2}, \mathrm{H}_{2} / \mathrm{CH}_{4}$ and $\mathrm{He} / \mathrm{N}_{2}$ are shown in Figure 2. Similar to Figure 1 , the dashed lines in Figure 2 represent one-quarter $( \pm 0.25)$, one-half $( \pm 0.5)$ and one $( \pm 1.0)$ order-ofmagnitude deviation of the predictions from experimental data. In addition, Table 3 lists the standard deviation $(\sigma)$ and average percent relative error $(E)$ values. Figure 2 indicates that the predictions fluctuate randomly about the mean (green line) without any clear bias, which implies the statistical 
analysis in Table 3 is sound. In Table 3, the largest $\sigma$ and $E$ values are for the $\mathrm{He} / \mathrm{N}_{2}$ gas pair, presumably due to the smallest number of polymers considered, whereas the smallest $\sigma$ and $\mathrm{E}$ values are for the $\mathrm{CO}_{2} / \mathrm{CH}_{4}$ gas pair, which is notably of great industrial interest in the gas separation field. The agreement of the selectivity values between experiments and predictions is likely because of (i) the use of large subunits representative of diamine and dianhydride for the repeat unit of a polyimide, as per the method of Alentiev et al. [16], and (ii) the accurate calculation of the molar volume of the subunits that accounted for effects such as intra-molecular interactions defined by the used force field type. This underscores that the chemical structure of the constituent repeat unit as well as configurations of subunits are dominant factors in the gas permeation properties of glassy polymers, since they dictate key parameters such as connectivity (meta, para, or ortho), symmetry, etc. that affect the resulting membrane separation properties significantly. 


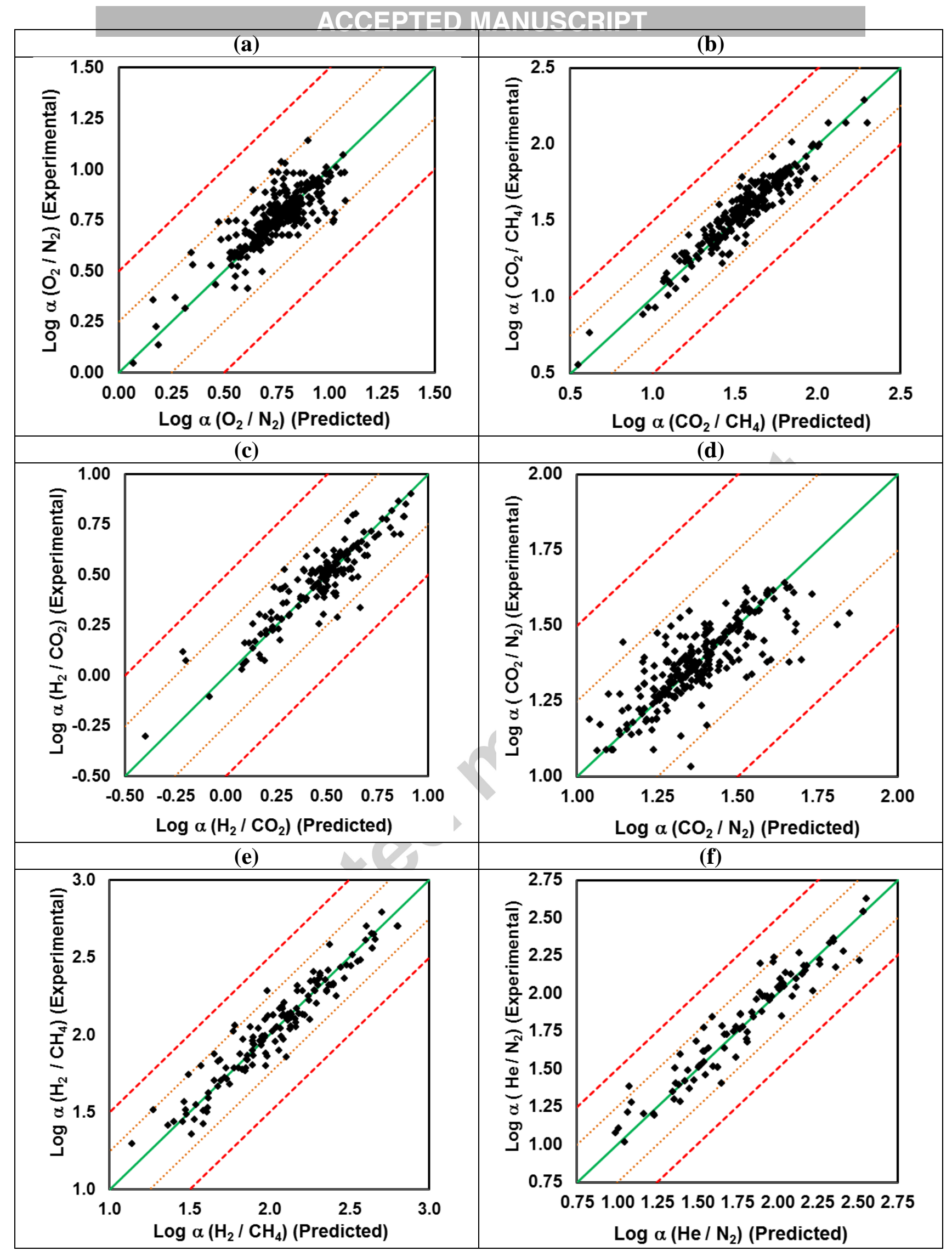

Figure 2. Comparison of experimental and predicted ideal selectivity coefficients calculated from the ratio of the permeability coefficients for (a) $\mathrm{O}_{2} / \mathrm{N}_{2}$, (b) $\mathrm{CO}_{2} / \mathrm{CH}_{4}$, (c) $\mathrm{H}_{2} / \mathrm{CO}_{2}$, (d) $\mathrm{CO}_{2} / \mathrm{N}_{2}$, (e) $\mathrm{H}_{2} / \mathrm{CH}_{4}$, and (f) $\mathrm{He} / \mathrm{N}_{2}$. 


$$
\text { ACCEPTED MANUSCRIPT }
$$

Table 3. Error analysis of the selectivity coefficients for different gas pairs calculated by the proposed method in this study. (The same formulas listed as footnotes in Table 2 are used.)

\begin{tabular}{|lcc|cccc|}
\hline & & & & & & \\
\hline$\sigma$ & 0.19 & 0.17 & 0.22 & 0.21 & 0.22 & 0.27 \\
\hline E & 12.9 & 12.7 & 16.2 & 13.9 & 17.6 & 20.8 \\
\hline Number of polymers & 311 & 255 & 177 & 271 & 144 & 93 \\
\hline
\end{tabular}

\subsection{Analysis of proposed copolyimide structures}

The possible combinations from the 32 dianhydrides and 75 diamines are enormous, therefore, we first identify the high-performing subunits, then specify that two out of the three subunits making up the copolyimide are the high-performing ones, and finally evaluate the performance of the resulting polymers. Specifically, in this part of the study, the better-performing subunits for each gas separation application (namely, $\mathrm{O}_{2} / \mathrm{N}_{2}, \mathrm{CO}_{2} / \mathrm{CH}_{4}, \mathrm{H}_{2} / \mathrm{CO}_{2}, \mathrm{CO}_{2} / \mathrm{N}_{2}, \mathrm{H}_{2} / \mathrm{CH}_{4}$, and $\mathrm{He} / \mathrm{N}_{2}$ ) are identified then analyzed in more depth. Firstly, for each gas pair, all the subunits considered are first plotted in terms of selectivity versus permeability to distinguish the dianhydride or diamine subunits with superior performance in terms of both selectivity and permeability. Secondly, these dianhydride subunits displaying superior performance are then paired with different subunits to make up different copolyimide structures for further assessment of the resulting performance. It should be noted that each copolyimide contains repeating units of dianhydride(1)/dianhydride(2)-diamine or dianhydridediamine(1)/diamine(2). Specifically, (i) the diamine/diamine or dianhydride/dianhydride ratios are set at a constant of 50/50, (ii) when the copolyimide is of the form dianhydride(1)/dianhydride(2)diamine, the superior dianhydride is set as dianhydride(1) in the repeating unit, while dianhydride(2) is any of the other dianhydrides and diamine is one of five diamines chosen based on either higher permeability or higher selectivity, and (iii) when the copolyimide is of the form dianhydridediamine(1)/diamine(2), the superior dianhydride is kept constant, diamine(1) is any of the 75 considered here, while diamine(2) is one of five diamines chosen based on either higher permeability or higher selectivity. Regarding (ii) and (iii), Table 4 explicitly lists the combinations used for the $\mathrm{O}_{2} / \mathrm{N}_{2}$ gas pair predictions. Notably, 6FDA is set as the first dianhydride for all gas pairs because of the general agreement that it is a remarkable monomer with unique transport properties. Thirdly, the evaluation of the performance of the proposed copolyimide structures is carried out to ascertain whether the upper permeability-selectivity bounds established in years 1991 and 2008 based on the trade-off between permeability and selectivity [27, 28] are exceeded, which is similar to the analysis reported earlier [17]. 
Therefore, all the figures in this section contains four sub-figures of selectivity versus permeability: (a) all subunits considered, (b) 6FDA-based copolyimides, and (c) and (d) for the copolyimides composed of a high-performing dianhydride each identified in (a). All the sub-figures (b) - (d) have the same ranges for the $x$-and $y$-axes for easier comparison. The analysis is valuable for providing insights into the fabrication of novel materials with better performance with respect to both selectivity and permeability for the separation of specific gas pairs.

\section{Analysis of the performance of copolyimides in $\mathrm{O}_{2} / \mathrm{N}_{2}$ separation}

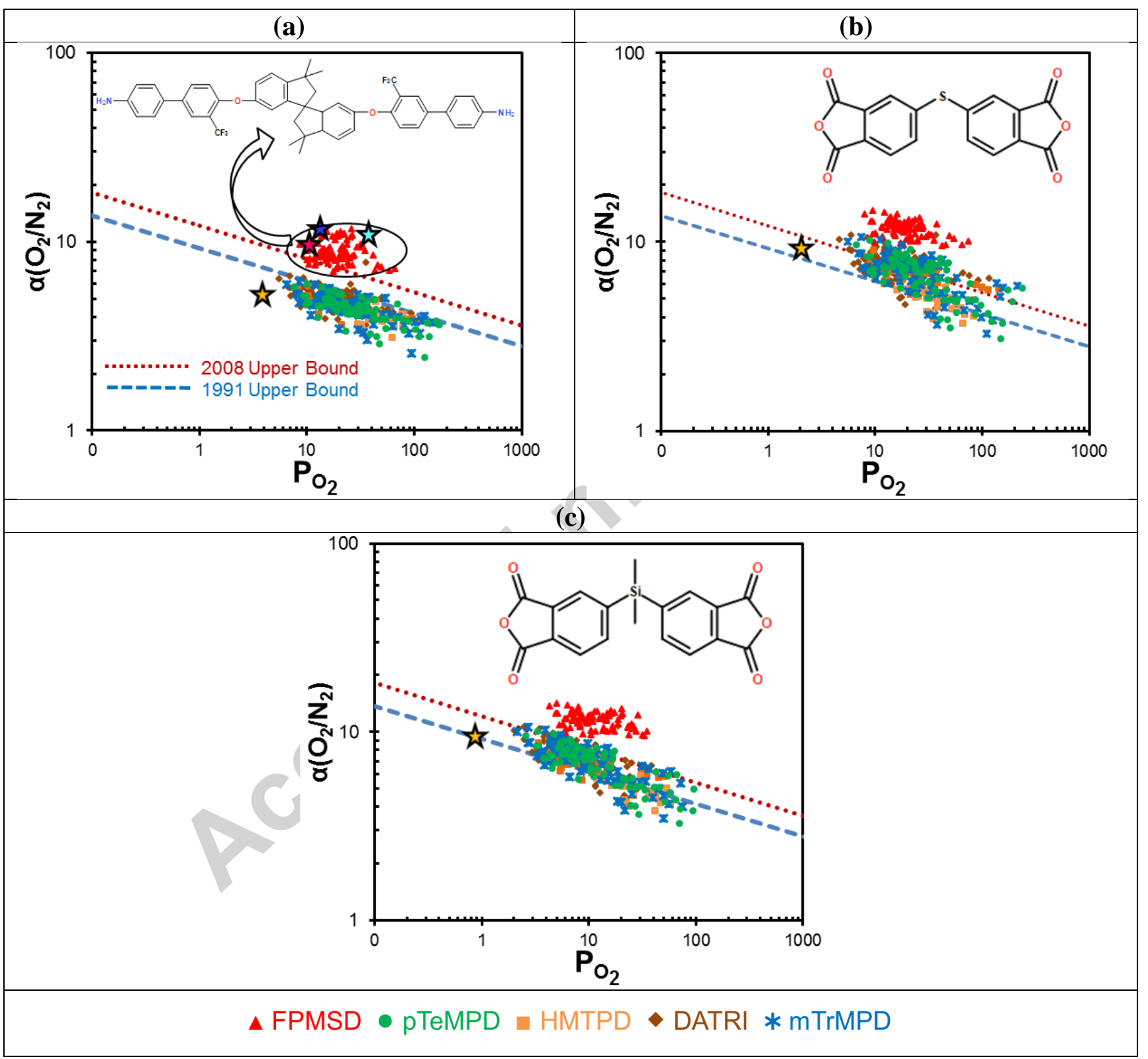

Figure 3. Predicted selectivity versus permeability diagrams of $\mathrm{O}_{2} / \mathrm{N}_{2}$ separation for (a) 6FDA-based copolyimides (star symbols with pink, blue, aqua and yellow color represent experimental transport properties of BPADA-FPMSD, 6FDA-FPMSD, ODPA-FPMSD, and 6FDA-ODA, respectively [38- 
40]), (b) pTDPA-based copolyimides (star symbol with yellow color represents experimental transport property of pTDPA-ODA [41]), and (c) SiDA-based copolyimides (star symbol with yellow color represents experimental transport property of SiDA-ODA [42]). The chemical structures of FPMSD, pTDPA, and SiDA are given in the inset of Figures (a), (b) and (c), respectively. The blue dashed and red dotted lines represent respectively the 1991 and 2008 upper bounds based on the selectivity-permeability tradeoff $[27,28]$.

Figure 3 presents the selectivity-permeability plots for the $\mathrm{O}_{2} / \mathrm{N}_{2}$ gas pair. The performance of the subunits shown in Figure A1 (a) shows that, other than 6FDA, pTDPA and SiDA exhibit higher permeability compared to other dianhydrides and comparable selectivity. Therefore, Figures 3 (a), (b) and (c) represent respectively the 6FDA-, pTDPA- and SiDA-based copolyimides. Additionally, while DATRI, HMTPD, mTrMPD and pTeMPD are selected as the diamines due to high permeability, FPMSD is chosen owing to high $\mathrm{O}_{2} / \mathrm{N}_{2}$ selectivity. It is desired in the membrane-based gas separation industry that the ideal membrane should have both high permeability and selectivity properties, however, a tradeoff inevitably exists in reality. For this reason, subunit combinations for the copolyimide construction are performed based on some subunits with high permeability and some with high selectivity. On the other hand, when the permeability contribution of each monomer or subunit is investigated, it is shown in Figure A1 (a) that, generally, high permeability stems from the diamine, while high selectivity arises from the dianhydride. All combinations to form a copolyimide from either dianhydride(1)/dianhydride(2)-diamine or dianhydridediamine(1)/diamine(2) are explicitly listed in Table 4 for clarification. Such details will not be given for subsequent gas pairs.

It should be noted that $\mathrm{O}_{2} / \mathrm{N}_{2}$ selectivity values of less than one are unrealistic, which is linked to the different permeabilities of the same polyimide reported in the literature due to solvent effects, annealing, imidization methods, etc. For instance, the 6FDA-mTrMPD polyimide is associated with nine different $\mathrm{O}_{2}$ permeability coefficients (inset in Figure A1 (a)) varying between 40 to 200 Barrer [29-37]. Because each $\mathrm{O}_{2}$ and $\mathrm{N}_{2}$ permeability value for the 6FDA-mTrMPD polyimide is included as an independent equation in the matrix of the system using Eq. 2, the large deviation in experimental values leads to the unrealistic $\mathrm{O}_{2} / \mathrm{N}_{2}$ selectivity values of lower than one, as is also the case for other polyimides. Notably, this compromises the accuracy of group contribution methods if the second type of polyimide is directly related to the polyimide with such scattered experimental data. As explained later in the section of "Analysis of the performance of copolyimides in $\mathrm{CO}_{2} / \mathrm{N}_{2}$ separation", such error can be mitigated in the current method by (i) increasing the number of 
different polyimides derived from the same dianhydride or diamine, and/or (ii) taking into consideration the factors (solvent type, synthesis route, residual solvent, etc.) that influence the membrane performance during synthesis. The experimental permeability coefficients of polyimides presented along with predicted permeabilities of copolyimides in Figure 3 clearly demonstrates the agreement between predicted and experimental values. For instance, Figure 3 (a) shows that the predicted data of the copolyimide constituted from 6FDA dianhydride and FPMSD diamine (red triangles) fall into the same region as the experimental data for 6FDA-FPMSD polyimide (blue star).

Table 4. Copolyimide combinations used in the predictive analysis of $\mathrm{O}_{2} / \mathrm{N}_{2}$ separation in Figure 3

\begin{tabular}{|c|c|c|c|c|c|c|}
\hline & Symbol & $\begin{array}{l}\text { Dianhydride } \\
\text { (1) }\end{array}$ & $\begin{array}{l}\text { Dianhydride } \\
\text { (2) }\end{array}$ & $\begin{array}{l}\text { Diamine } \\
\text { (1) }\end{array}$ & $\begin{array}{l}\text { Diamine } \\
\text { (2) }\end{array}$ & \\
\hline \multirow{2}{*}{1} & \multirow{2}{*}{$\diamond$} & 6 FDA & all others* & DATRI & & \multirow{10}{*}{ 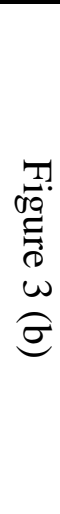 } \\
\hline & & 6FDA & - & DATRI & all others* & \\
\hline \multirow{2}{*}{2} & \multirow{2}{*}{ घ } & 6FDA & all others* & HMTPD & & \\
\hline & & 6FDA & - & HMTPD & all others* & \\
\hline \multirow{2}{*}{3} & \multirow{2}{*}{ * } & 6FDA & all others* & mTrMPD & - & \\
\hline & & 6FDA & - & mTrMPD & all others* & \\
\hline \multirow{2}{*}{4} & \multirow{2}{*}{$\bullet$} & 6FDA & all others* & pTeMPD & - & \\
\hline & & 6FDA & - & pTeMPD & all others* & \\
\hline \multirow{2}{*}{5} & \multirow{2}{*}{$\boldsymbol{\Delta}$} & 6FDA & all others* & FPMSD & - & \\
\hline & & 6FDA & - & FPMSD & all others* & \\
\hline \multirow{2}{*}{6} & \multirow{2}{*}{$\diamond$} & pTDPA & all others* & DATRI & - & \multirow{10}{*}{ 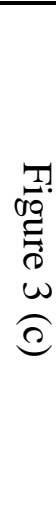 } \\
\hline & & pTDPA & - & DATRI & all others* & \\
\hline \multirow{2}{*}{7} & \multirow{2}{*}{ च } & pTDPA & all others* & HMTPD & - & \\
\hline & & pTDPA & - & HMTPD & all others* & \\
\hline \multirow{2}{*}{8} & \multirow{2}{*}{$*$} & pTDPA & all others* & mTrMPD & - & \\
\hline & & pTDPA & - & mTrMPD & all others* & \\
\hline \multirow{2}{*}{9} & \multirow{2}{*}{$\bullet$} & pTDPA & all others* & pTeMPD & - & \\
\hline & & pTDPA & - & pTeMPD & all others* & \\
\hline \multirow{2}{*}{10} & \multirow{2}{*}{$\boldsymbol{\Delta}$} & pTDPA & all others* & FPMSD & - & \\
\hline & & pTDPA & - & FPMSD & all others* & \\
\hline \multirow{2}{*}{11} & \multirow{2}{*}{$\downarrow$} & SiDA & all others* & DATRI & - & \multirow{10}{*}{ 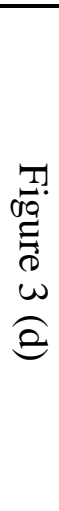 } \\
\hline & & SiDA & - & DATRI & all others* & \\
\hline \multirow{2}{*}{12} & \multirow{2}{*}{ च } & SiDA & all others* & HMTPD & - & \\
\hline & & $\mathrm{SiDA}$ & - & HMTPD & all others* & \\
\hline \multirow{2}{*}{13} & \multirow{2}{*}{$*$} & SiDA & all others* & mTrMPD & - & \\
\hline & & $\mathrm{SiDA}$ & - & mTrMPD & all others* & \\
\hline \multirow{2}{*}{14} & & SiDA & all others* & pTeMPD & - & \\
\hline & $\bullet$ & SiDA & - & pTeMPD & all others* & \\
\hline & & SiDA & all others* & FPMSD & - & \\
\hline 15 & $\boldsymbol{\Delta}$ & SiDA & - & FPMSD & all others* & \\
\hline
\end{tabular}

* Other dianhydrides or diamines considered in this study 
It is evident from Figure 3 that both the upper bounds based on the selectivity-permeability tradeoff can be exceeded by the judicious selection of dianhydrides and diamines as subunits to make up the copolyimides, which thereby provides recommendations for the synthesis of such polyimides to enhance $\mathrm{O}_{2} / \mathrm{N}_{2}$ separation. Figure 3 (a) shows that, although the 6FDA-based copolyimides largely fall below even the 1991 bound, those with the FPMSD diamine surpass the 2008 bound by having better selectivity comparatively. Although the copolyimides represented by the same symbol are composed of the same two high-performing subunits, the third subunit is different (refer to Table 4), which leads to the scatter of data. This indicates the non-negligible influence of the third constituent subunit on the performance of the resulting copolyimide. As for the pTDPA-based and SiDA-based copolyimides respectively in Figures 3 (b) and (c), (i) the performance is generally superior to that of the 6FDA-based copolyimides (Figure 3 (a)) in terms of largely exceeding the 1991 bound particularly with higher selectivity, and (ii) FPMSD persists in conferring the best performance, surpassing the 2008 bounds by greater extents than that of other subunits (Figure A1 (a)). Regarding FPMSD, the only report available in the literature combining it with 6FDA, BPADA and ODPA dianhydrides (star symbols with blue, pink and aqua colors in Figure 3 (a) respectively), also indicated high $\mathrm{O}_{2} / \mathrm{N}_{2}$ performance for these three polyimides with selectivity of about 10 [38], the value of which agrees with Figure A1 (a). However, one can get even higher selectivity of about 50\% more (i.e., 15) by coupling FPMSD with other dianhydrides like either pTDPA (Figure 3 (b)) or SiDA (Figure 3 (c)). In addition, the $\mathrm{O}_{2} / \mathrm{N}_{2}$ selectivity enhancement can be revealed by the comparison of experimental transport properties of polyimides derived from commonly-used diamine type in the literature like ODA (star symbols with yellow color represent 6FDA-ODA, pTDPA-ODA, and SiDA-ODA respectively in Figures 3 (a), (b) and (c)). The percent relative error of $\mathrm{O}_{2}$ and $\mathrm{N}_{2}$ permeabilities for 6FDA-ODA, pTDPA-ODA, and SiDA-ODA polyimides differ from 0.3 to $5.9 \%$. For the membrane-based gas separation industry, increase in either permeability or selectivity represents lower operating cost. Collectively, the results demonstrate that the application of the group contribution method is straightforward and insightful in providing guidance on the tailoring of polymers for specific applications. 


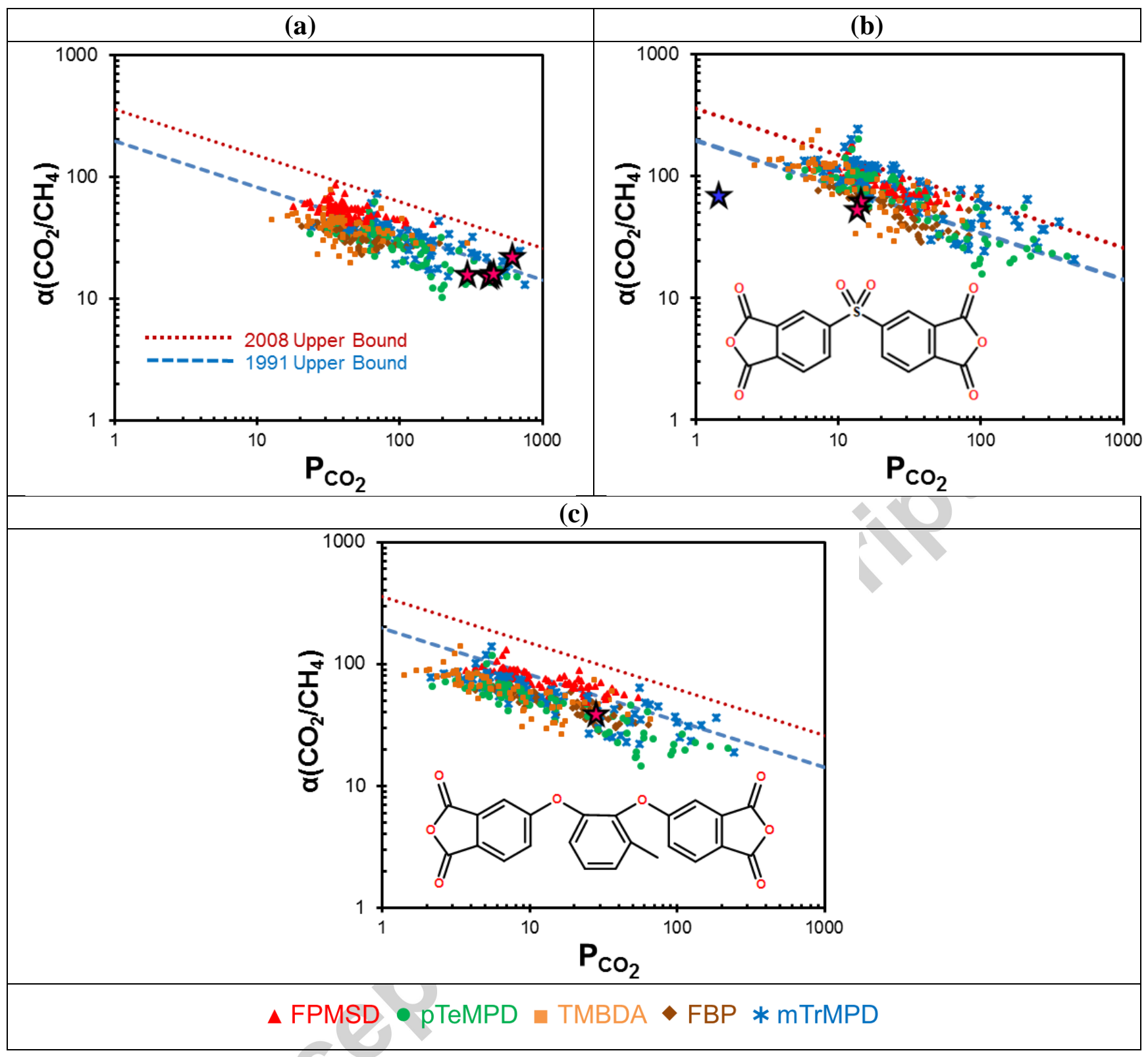

Figure 4. Predicted selectivity versus permeability diagrams of $\mathrm{CO}_{2} / \mathrm{CH}_{4}$ separation for (a) 6FDAbased copolyimides (star symbols with pink color represent available experimental transport properties of 6FDA-pTeMPD [29, 33, 43-45]), (b) DSDA-based copolyimides, with the inset showing the chemical structure of DSDA (star symbols with blue and pink color represent experimental transport property of respectively DSDA-BAPS and DSDA-DDBT [46-48]), and (c) 3MCADPA-based copolyimides, with the inset showing the chemical structure of 3MCADPA (star symbol with pink color represents experimental transport property of 3MCADPA-pTeMPD [49]). The blue dashed and red dotted lines represent respectively the 1991 and 2008 upper bounds based on the selectivity-permeability tradeoff [27, 28]. 
Analogous to Figure 3, Figure 4 displays the selectivity versus permeability plots for $\mathrm{CO}_{2} / \mathrm{CH}_{4}$ separation. Figure A1 (b) indicates that the most promising subunits are the 6FDA (Figure 4 (a)), DSDA (Figure 4 (b)) and 3MCADPA (Figure 4 (c)) dianhydrides; additionally, the diamines TMBDA, mTrMPD and pTeMPD are selected due to their high permeability performance, and FBP and FPMSD are chosen owing to high selectivity performance compared to other diamine subunits. In contrast to Figure A1 (a), much fewer subunits exceed the upper bound in Figure A1 (b), which suggests that more improvements for $\mathrm{CO}_{2} / \mathrm{CH}_{4}$ separation is needed. Despite the rapid progress in membrane fabrication, $\mathrm{CO}_{2} / \mathrm{CH}_{4}$ separation application so far is limited to novel monomers.

The same deduction in the analysis of $\mathrm{O}_{2} / \mathrm{N}_{2}$ selectivity can be made regarding the $\mathrm{CO}_{2} / \mathrm{CH}_{4}$ selectivity values of less than one in Figure A1 (b), whereby the inset shows that the 6FDAmTrMPD polyimide has eight different $\mathrm{CO}_{2}$ permeability coefficients in the wide range of 150 and 850 Barrer. This is also the case for the 6FDA-pTeMPD polyimide, whereby the experimental $\mathrm{CO}_{2}$ permeability coefficients range from 300 to 615 Barrer (pink stars in Figure 4 (a)). The corresponding predicted $\mathrm{CO}_{2}$ permeability coefficient is 380 Barrer with minimum, average and maximum percent relative errors of 10.2, 20.7 and 40.7, respectively, which underlies the similar error values obtained in the study of Robeson et al. [1, 18] that only included a smaller number of polyimides. Nevertheless, coherence between experimental and predicted values is apparent in Figure 4 (a). It is well-known that the 6FDA-mTrMPD and 6FDA-pTeMPD polyimides exhibit the highest $\mathrm{CO}_{2}$ permeability values among the polyimides reported in the literature, so it is expected that the experimental $\mathrm{CO}_{2}$ permeability of the 6FDA-pTeMPD polyimide should have higher x-axis values, as explicit in Figure 4 (a).

It is evident in Figure 4 that the copolyimides largely fall below the 2008 bound, which implies that even the combinations of better performing subunits fall short of improving such separations. While the 6FDA-based copolyimides congregate around the 1991 upper bound without exceeding the 2008 upper bound (Figure 4 (a)), the 3MCADPA-based copolyimides perform even worse with a larger proportion being below the 1991 bound (Figure 4 (c)). Among the three high performing dianhydride subunits (Figure 4 (a) - (c)), the DSDA-based copolyimides performs the best with most falling in between the two bounds and particularly those with the mTrMPD diamine surpassing the 2008 upper bound. The performance of the mTrMPD diamine in polyimide membranes for $\mathrm{CO}_{2} / \mathrm{CH}_{4}$ separation has been widely reported, and has been attributed to the large d-spacing value due to three $-\mathrm{CH}_{3}$ groups connected to the phenyl ring in the mTrMPD moiety, which increases the free volume of the polymer and thereby increases permeability $[7,8,10,50]$. The mTrMPD diamine is generally seen to give superior performance for $\mathrm{CO}_{2} / \mathrm{CH}_{4}$ throughout Figures 4 (a) - (c) in some combinations of 
copolyimides. Comparing the predicted sub-unit contributions of 6FDA and 3MCADPA in Figure A1 (b), 6FDA has high permeability but low selectivity compared to 3MCADPA. When we combine these two dianhydrides with the same diamine like pTeMPD, the experimental values exhibit the same trends, specifically. 6FDA-pTeMPD has high $\mathrm{CO}_{2}$ permeability and low $\mathrm{CO}_{2} / \mathrm{CH}_{4}$ selectivity compared to 3MCADPA-pTeMPD. This indicates the consistency of our predictions with experiments. $\mathrm{CO}_{2} / \mathrm{CH}_{4}$ selectivity enhancement can be easily obtained by coupling existing diamines with the DSDA dianhydride (which confers superior $\mathrm{CO}_{2} / \mathrm{CH}_{4}$ selectivity). Experimental performance of some DSDA-based polyimides is given in Figure 4 (b) as an example (star symbols with blue and pink color represent experimental transport property of DSDA-BAPS and DSDADDBT, respectively). 


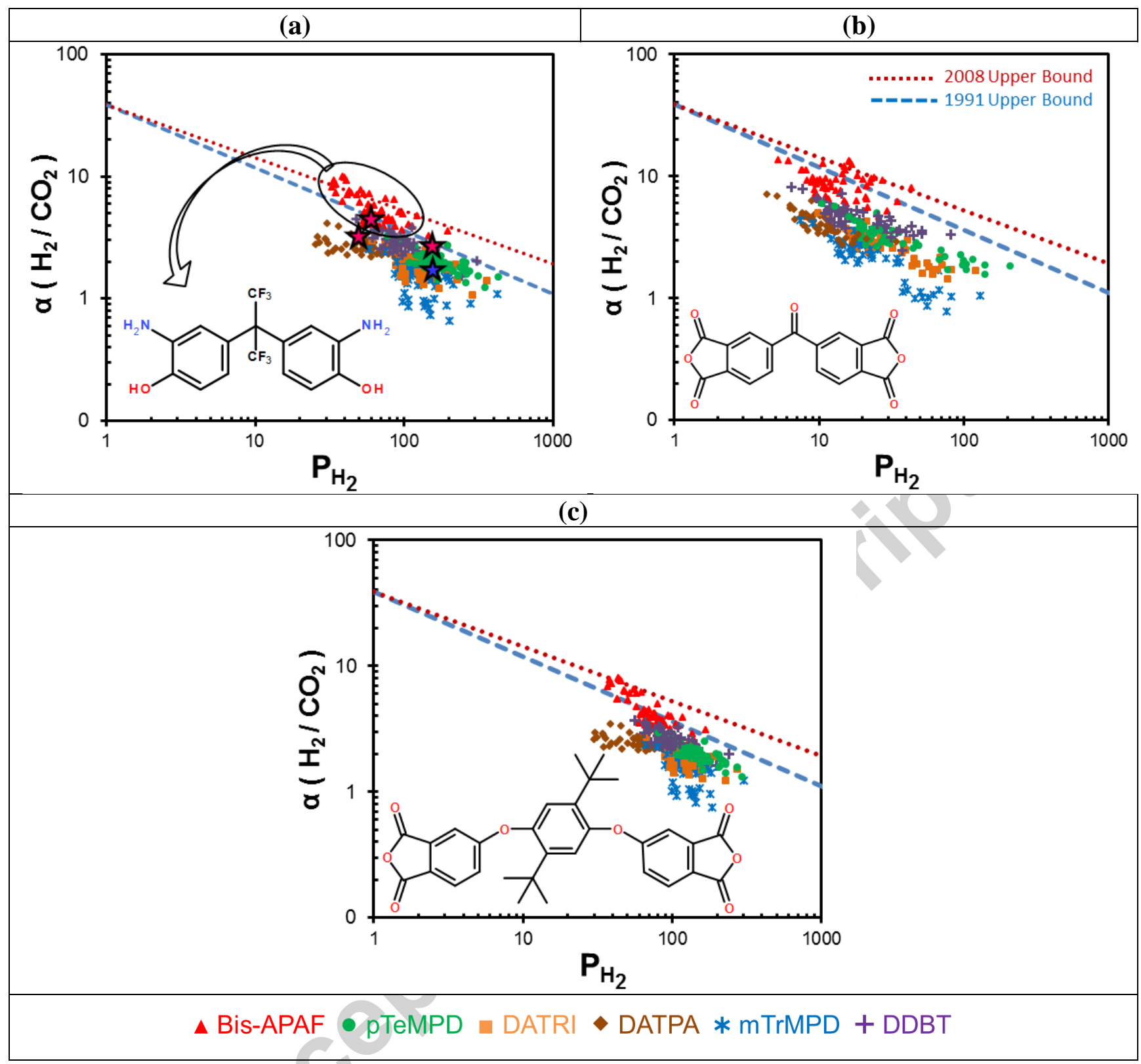

Figure 5. Predicted selectivity versus permeability diagrams of $\mathrm{H}_{2} / \mathrm{CO}_{2}$ separation for (a) $6 \mathrm{FDA}$ based copolyimides (star symbols with pink and blue color represent experimental transport properties of 6FDA-bis-APAF polyimides and 6FDA-bis-APAF/mTrMPD copolyimide, respectively [51-53]), (b) BTDA-based copolyimides, and (c) DTBHQDPA-based copolyimides. The chemical structures of Bis-APAF, BTDA and DTBHQDPA are given in the insets of Figures (a), (b) and (c), respectively. The blue dashed and red dotted lines represent respectively the 1991 and 2008 upper bounds based on the selectivity-permeability tradeoff $[27,28]$. 
Figure 5 presents the selectivity versus permeability plots for $\mathrm{H}_{2} / \mathrm{CO}_{2}$ separation. Three observations are highlighted here. Firstly, Figure A1 (c) shows that all dianhydride subunits are above the upper bound, with most exhibiting low permeability behavior. The dianhydride with the highest selectivity (namely, BTDA) and two with the highest permeability (namely, 6FDA and DTBHQDPA) are selected for further assessment in Figures 5 (a) - (c). In contrast, all diamines are below the upper bound; nonetheless, those with higher selectivity (namely, bis-APAF and DATPA) and higher permeability (namely, DATRI, DDBT, mTrMPD and pTeMPD) are selected for analysis. Secondly, similar to that for $\mathrm{CO}_{2} / \mathrm{CH}_{4}$ separation (Figure 4), the copolyimides fall below but close to the 2008 upper bound with the monomers available in the literature in Figure 5, despite the consideration of the best-performing dianhydrides and diamines. Compared to the 6FDA dianhydride (Figure 5 (a)), the BTDA dianhydride (Figure 5 (b)) confers lower permeability, while the DTBHQDPA dianhydride (Figure 5 (c)) leads to similar but smaller ranges of both selectivity and permeability. This indicates that the 6FDA-based copolyimides seem most promising in the $\mathrm{H}_{2} / \mathrm{CO}_{2}$ separation application. Thirdly, the bis-APAF diamine stands out in terms of giving copolyimides that are closest to and with some exceeding the 2008 bound. Recently, a new class of thermally-modified aromatic polyimides, in which the diamine is either bis-APAF or mHAB, has emerged as a prominent membrane material in gas separation $[54,55]$. With respect to the effect of bis-APAF, it is hypothesized that the attendant changes in molecular connectivity and conformation that alter chain packing leads to an unique free volume distribution and rigid structure, which is crucial to enabling thermal modification and obtaining insoluble polybenzoxazoles (PBOs) membranes that exhibit exceptional thermal and chemical resistance. The results here affirm that bis-APAF is a beneficial amine in copolyimides for $\mathrm{H}_{2} / \mathrm{CO}_{2}$ separation application. On the other hand, Figure 5 (a) shows that the experimental $\mathrm{H}_{2}$ permeability coefficient of 6FDA-bis-APAF polyimide (pink stars) fall into the region of the group of copolyimide constituted from 6FDA dianhydride and bis-APAF diamine (red triangles). In addition, Figure 5 (a) indicates that the experimental $\mathrm{H}_{2}$ permeability of 6FDA-bisAPAF/mTrMPD copolyimide (blue star) is 156 Barrer which is exactly the same as that predicted, and the experimental and predicted $\mathrm{H}_{2} / \mathrm{CO}_{2}$ selectivity is respectively 1.8 and 2.7. These observations affirm the predictive capability of group contribution models.

In particular for $\mathrm{H}_{2} / \mathrm{CO}_{2}$ separation, the membrane should be equipped with the ability to discriminate the small difference in the kinetic diameters of $\mathrm{H}_{2}$ and $\mathrm{CO}_{2}$, and/or preferentially adsorb $\mathrm{H}_{2}$ compared to $\mathrm{CO}_{2}$. While molecular dynamics simulation is informative on the choice of dianhydrides and diamines to enhance the performance of copolyimides in $\mathrm{H}_{2} / \mathrm{CO}_{2}$ separation, further advances in molecular design will improve membranes for such gas separation applications. 


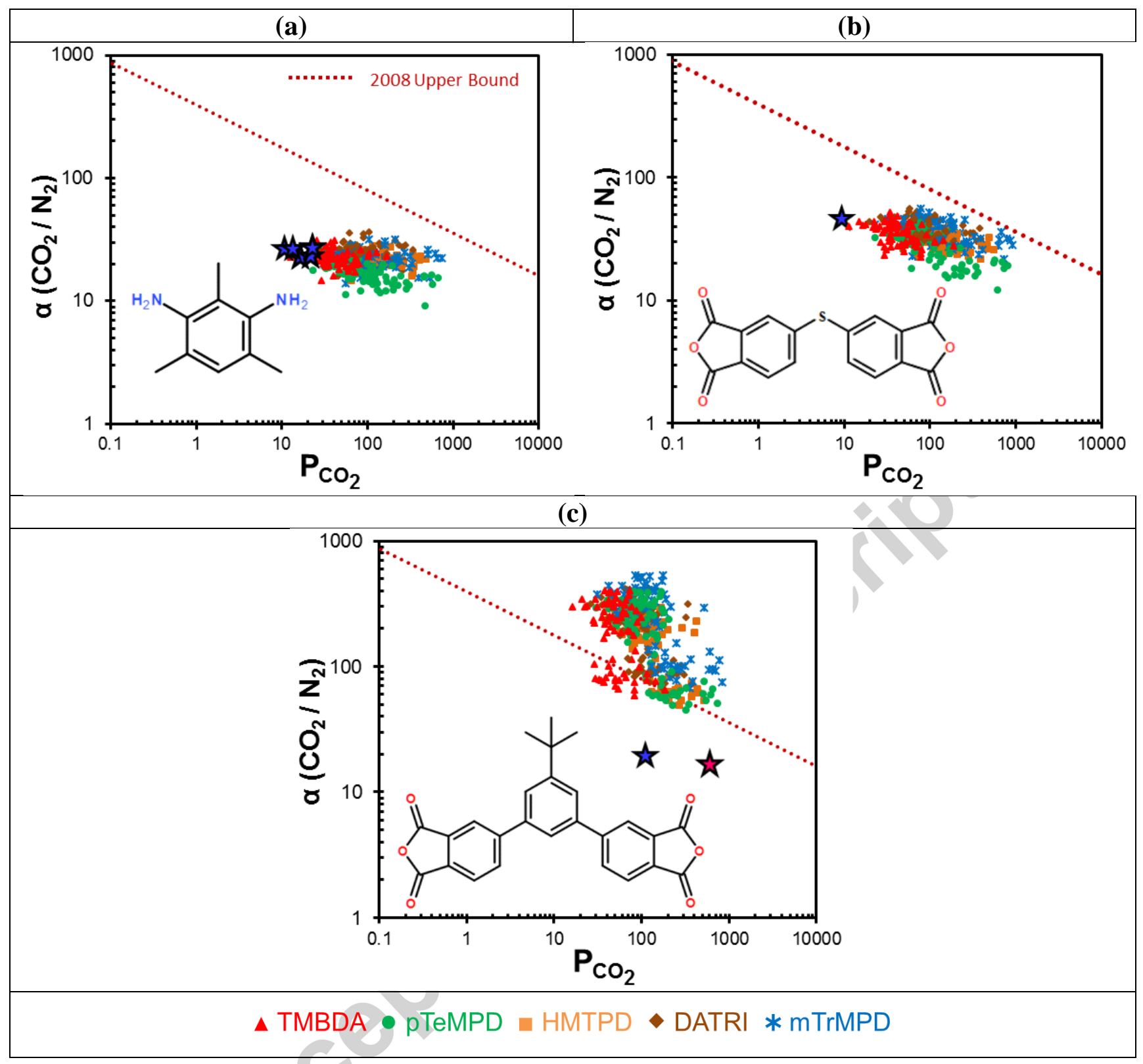

Figure 6. Predicted selectivity versus permeability diagrams of $\mathrm{CO}_{2} / \mathrm{N}_{2}$ separation for (a) 6FDAbased copolyimides, with the inset showing the chemical structure of mTrMPD (star symbols with blue color represent experimental transport properties of various 6FDA-ODA polyimides [39, 40, 5660]), (b) pTDPA-based copolyimides, with the inset showing the chemical structure of pTDPA (star symbol with blue color represents experimental transport property of pTDPA-ODA [41]), and (c) BTPDA-based copolyimides, with the inset showing the chemical structure of BTPDA (star symbols with pink and blue colors represent experimental transport property of BTPDA-mTrMPD and BTPDA-6FpDA, respectively [61]). The red dotted line represents the 2008 upper bound based on the selectivity-permeability tradeoff; the 1991 study did not investigate $\mathrm{CO}_{2} / \mathrm{N}_{2}$ separation [27, 28]. 
Figure 6 depicts the selectivity-permeability information for $\mathrm{CO}_{2} / \mathrm{N}_{2}$ separation. It should be noted that the 1991 upper bound is not shown in Figures 6 (a) - (c) because the $\mathrm{CO}_{2} / \mathrm{N}_{2}$ separation was not included in the study [27]. Figure A1 (d) shows clearly that only a few subunits are above the upper bound, which indicates the limited performance of the available subunits for the $\mathrm{CO}_{2} / \mathrm{N}_{2}$ gas pair and suggests the need for further improvements. Accordingly, in this study, higher performing subunits are chosen to customize the copolyimides to enhance the $\mathrm{CO}_{2} / \mathrm{N}_{2}$ separation. The 6FDA, BTPDA and pTDPA dianhydrides are identified for the high permeability, while the DATRI, HMTPD, TMBDA, mTrMPD and pTeMPD diamines are identified for the high $\mathrm{CO}_{2} / \mathrm{N}_{2}$ selectivity. Among the three dianhydrides assessed (Figures 6 (a) - (c)), pTDPA (Figure 6(b)) gave better performance then 6FDA (Figure 6(a)), both of which are below the 2008 bound. Experimental $\mathrm{CO}_{2} / \mathrm{N}_{2}$ selectivity is enhanced with the incorporation of the pTDPA-ODA polyimide (blue star in Figure 6 (b)) instead of 6FDA-ODA (blue stars in Figure 6 (a)), which is evident in Figure A1 (d). As for diamines, the mTrMPD noticeably gives better performance with all three dianhydrides considered (Figures 6 (a) (c)).

In the literature, seven different polyimides constituted by the BTPDA dianhydride have been synthesized, and shown to give reasonable performance for $\mathrm{O}_{2} / \mathrm{N}_{2}$ and $\mathrm{CO}_{2} / \mathrm{CH}_{4}$ separations, but $\mathrm{CO}_{2} / \mathrm{N}_{2}$ separation was not investigated [61-63]. Two polyimides, namely, BTPDA-mTrMPD and BTPDA-6FpDA (pink and blue stars in Figure 6 (c), respectively), have reported $\mathrm{O}_{2}, \mathrm{~N}_{2}, \mathrm{CO}_{2}$ and $\mathrm{CH}_{4}$ permeability coefficients from which $\mathrm{CO}_{2} / \mathrm{N}_{2}$ selectivity can be calculated. Although BTPDA dianhydride displays high performance in Figure A1 (d), two experimental $\mathrm{CO}_{2} / \mathrm{N}_{2}$ selectivities associated with these polyimides fall well below the performance of the copolyimide group (Figure 6 (c)) derived from BTPDA dianhydride. It is evident in Figure 3 for $\mathrm{O}_{2} / \mathrm{N}_{2}$ separation that group contribution methods may mislead if the second type of polyimide is directly related to the polyimide that has scattered experimental data that leads to unrealistic selectivity values, and has very few experimental data derived from the novel monomer. For example, the 6FDA-mTrMPD (or any polyimide including mTrMPD diamine) polyimide has scattered data which leads to increased error associated with the mTrMPD diamine, as is also the case for the 6FpDA diamine. Correspondingly, the permeability contribution of BTPDA for BTPDA-mTrMPD and BTPDA-6FpDA polyimides should benefit from the permeability contribution of mTrMPD and 6FpDA diamines, respectively. The results will lead to a higher contribution for BTPDA due to the lower contribution of mTrMPD in order to yield comparable predicted permeability of BTPDA-mTrMPD with experimental results. The error can be mitigated by increasing the number of different polyimides derived from the BTPDA dianhydride and/or taking into consideration the factors that influence the membrane performance in synthesis. 


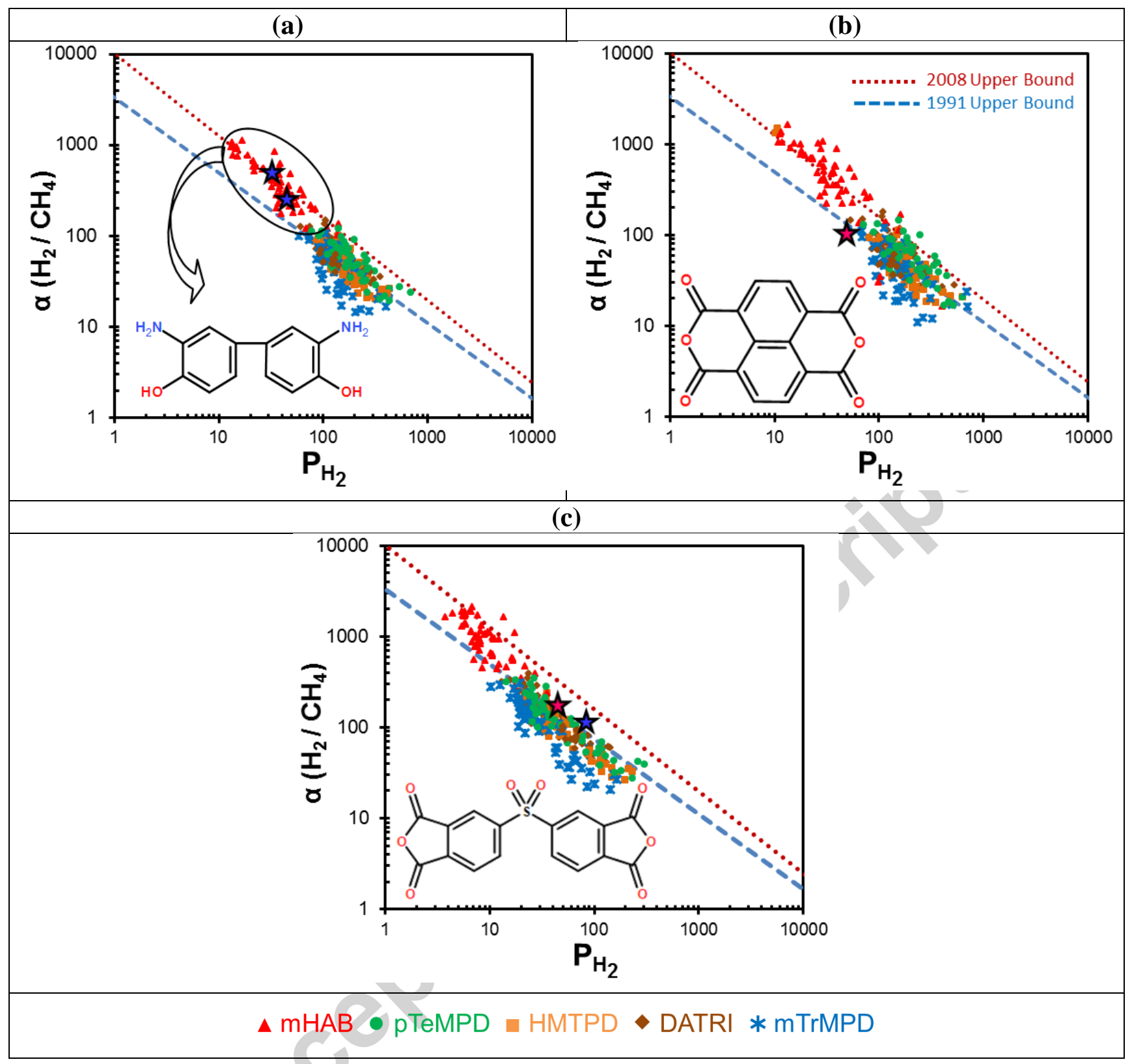

Figure 7. Predicted selectivity versus permeability diagrams of $\mathrm{H}_{2} / \mathrm{CH}_{4}$ separation for (a) 6FDAbased copolyimides (star symbols with blue color represent experimental transport properties of 6FDA-mHAB polyimides [64, 65]), (b) NTDA-based copolyimides (star symbol with pink color represents experimental transport property of NTDA-BAPHF [66]), and (c) DSDA-based copolyimides (star symbols with pink and blue color represent experimental transport properties of DSDA-DDBT polyimide and DSDA/TADATO-DDBT copolyimide, respectively [48, 67]). The chemical structures of mHAB, NTDA and DSDA are given in the insets of Figures (a), (b) and (c), respectively. The blue dashed and red dotted lines represent respectively the 1991 and 2008 upper bounds based on the selectivity-permeability tradeoff $[27,28]$. 
Figure 7 presents the analysis for the $\mathrm{H}_{2} / \mathrm{CH}_{4}$ separation application. Figure A1 (e) shows that all dianhydride subunits lie above the upper bound, exhibiting low permeability but high selectivity; the dianhydride with the highest selectivity (namely, DSDA) and two with highest permeability (namely, 6FDA and NTDA) are selected for further analysis is Figures 7 (a) - (c). As for the diamines, all fall below the upper bound; nonetheless, DATRI, HMTPD, mTrMPD and pTeMPD are selected for high permeability, and mHAB is selected for high selectivity. It is worth noting that the sulphonecontaining dianhydrides have been identified as giving superior performance, such as DSDA in $\mathrm{H}_{2} / \mathrm{CH}_{4}$ (Figure 7), $\mathrm{CO}_{2} / \mathrm{N}_{2}$ (Figure 6) and $\mathrm{CO}_{2} / \mathrm{CH}_{4}$ (Figure 4) separations, and pTDPA in $\mathrm{CO}_{2} / \mathrm{N}_{2}$ (Figure 6) and $\mathrm{O}_{2} / \mathrm{N}_{2}$ (Figure 3) separations. A previous study also concluded that copolyimides derived from the sulphone containing diamines such as BAPS and pDDS exhibit outstanding properties [17].

Based on Figure 7, with combinations of high performing dianhydrides and diamines, the resulting copolyimides lie close to but below the 2008 upper bound like the case of $\mathrm{H}_{2} / \mathrm{CO}_{2}$ (Figure 5). Among the three dianhydrides, the DSDA-based copolyimides (Figure 7 (c)) performed the worst, with many falling even below the 1991 upper bound, while both 6FDA-based (Figure 7 (a)) and NTDA-based copolyimides (Figure 7 (b)) perform similarly. Among the diamines, the mHAB, which, as with bisAPAF (with high performance in $\mathrm{H}_{2} / \mathrm{CO}_{2}$ separation (Figure 5)), is mainly used in the literature as a precursor for thermally rearranged polymers, enhances the performance of the copolyimide for $\mathrm{H}_{2} / \mathrm{CO}_{2}$ separation. In addition, Figure 5 (a) shows that the experimental coefficients of 6FDAmHAB polyimides (blue stars) fall into the region of the predicted coefficients belonging to the group of copolyimide derived from 6FDA dianhydride and mHAB diamine (red triangles), revealing consistency between predicted and experimental values. 


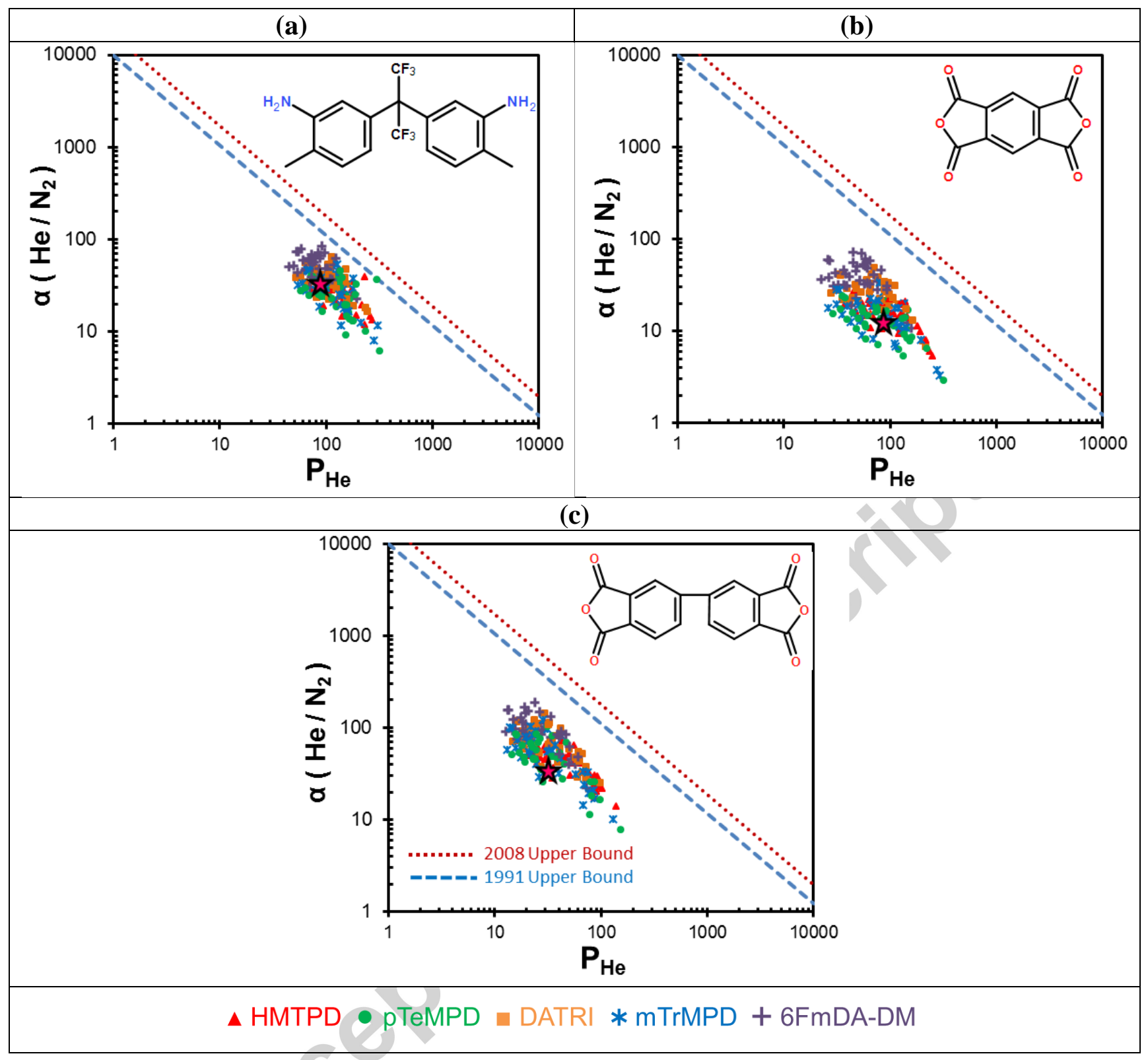

Figure 8. Predicted selectivity versus permeability diagrams of $\mathrm{He} / \mathrm{N}_{2}$ separation for (a) 6FDA-based copolyimides (star symbol with pink color represents experimental transport property of PTPDA6FmDA-DM [61]), (b) PMDA-based copolyimides (star symbol with pink color represents experimental transport property of PMDA-TMMDA [40]), and (c) BPDA-based copolyimides (star symbol with pink color represents experimental transport property of BPDA-TMMDA [40]). The chemical structures of 6FmDA-DM, PMDA and BPDA are given in the insets of Figures (a), (b) and (c), respectively. The blue dashed and red dotted lines represent the upper bounds based on the selectivity-permeability tradeoff $[27,28]$. 
Figure 8 presents the analysis for $\mathrm{He} / \mathrm{N}_{2}$ separation. In Figure A1 (f), the 6FDA, PMDA and BPDA dianhydrides and the DATRI, HMTPD, 6FmDA-DM, mTrMPD and pTeMPD diamines are selected for further analysis due to the comparatively higher permeability. According to Figure 8, the all copolyimides fall below even the 1991 bound for $\mathrm{He} / \mathrm{N}_{2}$ separation. Although the 6FDA, PMDA and BPDA dianhydrides are above the upper bound in Figure A1 (f), they perform poorly when combined with other monomers to yield copolyimides. With respect to diamines, copolyimides constituted from 6FmDA-DM, which have been reported by two studies in literature [61, 68], offer higher selectivity consistently in Figures 8 (a) - (c). It is worth noting that the predicted and experimental He permeability and $\mathrm{He} / \mathrm{N}_{2}$ selectivity values of PTPDA-6FmDA-DM (pink star in Figure 8 (a)) are exactly same.

\section{Conclusions and Recommendations}

The volume-based group contribution approach proposed by Robeson et al. [1] is reutilized for the extended dataset of polyimide and copolyimide structures to predict gas transport characteristics like permeability and selectivity of $\mathrm{He}, \mathrm{H}_{2}, \mathrm{O}_{2}, \mathrm{~N}_{2}, \mathrm{CO}_{2}$ and $\mathrm{CH}_{4}$. Comparisons between the predicted and experimental data show that the average percent relative error is between $9.2 \%$ and $21.2 \%$ for permeability, and $12.7 \%$ and $20.8 \%$ for selectivity, which are similar to those by Robeson et al. [1, 18] despite a much larger number of polymers considered. The improvement is due to the (i) use of larger subunits which not only account for specifications of the whole chemical structure but also the spatial organization of the molecules, (ii) means of accounting for the contribution of the subunits based on molar volume rather than empirical factors, (iii) the expanded database, and (iv) the focus on a particular polymer class like polyimide and copolyimide rather than a wide range of polymers.

High-performing subunits are identified after screening through those available in literature, then used to combine into new copolyimides, whose performance are evaluated based on comparing with the selectivity-permeability trade-off bound [27, 28]. The separation of the commercially relevant gas pairs, namely, $\mathrm{O}_{2} / \mathrm{N}_{2}, \mathrm{CO}_{2} / \mathrm{CH}_{4}, \mathrm{H}_{2} / \mathrm{CO}_{2}, \mathrm{H}_{2} / \mathrm{CH}_{4}, \mathrm{CO}_{2} / \mathrm{N}_{2}$ and $\mathrm{He} / \mathrm{N}_{2}$, are used for the assessment. The results show that a judicious selection and combination of existing high-performing monomers is beneficial for exceeding the selectivity-permeability trade-off bound for $\mathrm{O}_{2} / \mathrm{N}_{2}$, $\mathrm{CO}_{2} / \mathrm{CH}_{4}, \mathrm{H}_{2} / \mathrm{CO}_{2}$ and $\mathrm{H}_{2} / \mathrm{CH}_{4}$ separation applications, whereas novel monomers and molecular design approaches are needed for $\mathrm{CO}_{2} / \mathrm{N}_{2}$ and $\mathrm{He} / \mathrm{N}_{2}$ separation applications. It should be noted that all three monomers constituting the copolyimide influence the resulting performance, as evident in the scatter of data when only two high-performing monomers were chosen while the third was 
ACCEPTED MANUSCRIPT

random. The predicted data points above the trade-off bounds are recommended for synthesis and validation of predictions. Summarized below are some monomer structures that can be easily designed to enhance the performance of copolyimide membranes:

- Sulphone-containing monomers, which have been highlighted in the literature due to their high sorption capacity, are also seen to perform well here in gas separation applications. While the DSDA monomer is advantageous in $\mathrm{H}_{2} / \mathrm{CH}_{4}, \mathrm{CO}_{2} / \mathrm{N}_{2}$, and $\mathrm{CO}_{2} / \mathrm{CH}_{4}$ separations, pTDPA is beneficial in $\mathrm{CO}_{2} / \mathrm{N}_{2}$ and $\mathrm{O}_{2} / \mathrm{N}_{2}$ separations, and mTDPA and DDBT in $\mathrm{O}_{2} / \mathrm{N}_{2}$ and $\mathrm{H}_{2} / \mathrm{CO}_{2}$ separations. By using sulphone groups in targeted molecular designs, it is possible to further improve performances.

- The widely known and used mTrMPD and pTeMPD monomers in the literature also exhibit their high permeability capacity here as well, due to the steric hindrance of the methyl side groups which lead to the increase in free volume and hence in permeability. The other monomers with methyl side groups are HMTPD and TMBDA, which have three and two phenyl rings respectively with two methyl groups in each phenyl. While the HMTPD outperforms in many separation applications like $\mathrm{O}_{2} / \mathrm{N}_{2}, \mathrm{H}_{2} / \mathrm{CH}_{4}, \mathrm{CO}_{2} / \mathrm{N}_{2}$, and $\mathrm{He} / \mathrm{N}_{2}$, TMBDA is successful in $\mathrm{CO}_{2} / \mathrm{CH}_{4}$ and $\mathrm{CO}_{2} / \mathrm{N}_{2}$ separations.

- The other well-known group of monomers is the ones used in thermally rearranged polymers which are promising in many gas separation applications due to their interconnected micro volumes and distinctive free volume morphologies. The monomers used in the precursor of thermally rearranged polymers demonstrate their importance here as well in $\mathrm{H}_{2} / \mathrm{CO}_{2}$ (namely, bis-APAF) and $\mathrm{H}_{2} / \mathrm{CH}_{4}$ (namely, mHAB) separations.

- The use of contorted monomers like spiro-centered (polymers of intrinsic microporosity (PIMs)) or bridged bicyclics (triptycene, ethanoanthracene and Tröger's base) are recently gaining much attention in membrane-based gas separation area due to the resulting highly ultramicroporous, solution-processable polymers [69]. In this study, the spiro-centered FPMSD performs well in $\mathrm{O}_{2} / \mathrm{N}_{2}$ and $\mathrm{CO}_{2} / \mathrm{CH}_{4}$ separations, and FBP in $\mathrm{CO}_{2} / \mathrm{CH}_{4}$ separation application, probably due to the spiro-center feature enabling ultramicroporosity. Owing to bridged bicyclics, DATRI shows up as a promising monomer in all separation applications studied except $\mathrm{CO}_{2} / \mathrm{CH}_{4}$.

This study presents a method for enhanced predictions of the perm-selectivity behavior of the current dataset and also other novel monomers used in the constitution of polyimides or copolyimides. For a new polyimide synthesized with a novel monomer, if gas permeability coefficients are measured for a gas pair studied here, it is straightforward to predict the performance when the monomer is combined with a range of different monomer structures at different ratios. This will be valuable in 
leading more systematic experimental studies. Besides being beneficial for novel polymeric monomers, this fast screening method is also important in selecting the continuous phase for mixedmatrix membranes. Finally, the use of group contribution methods is a more advantageous polymer screening approach than the molecular simulation techniques for membrane based gas separation, since the latter necessitate much more time to even characterize one structure. Moreover, in spite of the recent progress in molecular simulation techniques to calculate the sorption properties of polymers, diffusion coefficients calculated by using simulation tools are not in good agreement with experimental properties in the literature, possibly due to the limited time span and/or ensemble size of the simulations, hence the statistical reliability of their results are poor [70].

Table 1. Predicted permeability data for structural units along with their molar volume comprising the group contribution approach

\begin{tabular}{|c|c|c|c|c|c|c|c|c|}
\hline Chemical structures of subunits & \multirow[b]{2}{*}{$\begin{array}{c}\text { Abbreviat } \\
\text { ion }\end{array}$} & \multirow{2}{*}{$\begin{array}{c}\text { Molec } \\
\text { ular } \\
\text { Volum } \\
\mathrm{e}\left(\AA^{3}\right) \\
\text { of } \\
\text { subuni } \\
\text { ts }\end{array}$} & \multicolumn{6}{|c|}{$\begin{array}{l}\text { Permeability (Barrer*) contribution of } \\
\text { subunits }\end{array}$} \\
\hline Dianhydrides & & & He & $\mathbf{H}_{2}$ & $\mathbf{O}_{2}$ & $\mathbf{N}_{2}$ & $\mathrm{CO}_{2}$ & $\mathrm{CH}_{4}$ \\
\hline & PMDA & $\begin{array}{c}157.4 \\
7\end{array}$ & 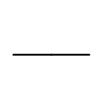 & 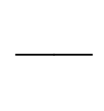 & $\begin{array}{c}0.187 \\
9\end{array}$ & $\begin{array}{c}0.038 \\
5\end{array}$ & $\begin{array}{c}3.703 \\
0\end{array}$ & $\begin{array}{c}0.012 \\
0\end{array}$ \\
\hline & NTDA & $\begin{array}{c}200.3 \\
9\end{array}$ & & $\begin{array}{c}769.8 \\
881\end{array}$ & $\begin{array}{c}0.674 \\
4\end{array}$ & $\begin{array}{c}1.067 \\
2\end{array}$ & $\begin{array}{c}13.09 \\
29\end{array}$ & $\begin{array}{c}0.034 \\
9\end{array}$ \\
\hline & BPDA & $\begin{array}{c}229.3 \\
8\end{array}$ & $\begin{array}{c}26.74 \\
10\end{array}$ & $\begin{array}{c}22.63 \\
64\end{array}$ & $\begin{array}{c}0.065 \\
5\end{array}$ & $\begin{array}{c}0.003 \\
0\end{array}$ & $\begin{array}{c}0.377 \\
2\end{array}$ & $\begin{array}{c}0.002 \\
5\end{array}$ \\
\hline & BTDA & $\begin{array}{c}250.1 \\
9\end{array}$ & $\begin{array}{c}21.09 \\
19\end{array}$ & $\begin{array}{c}19.15 \\
26\end{array}$ & $\begin{array}{c}0.046 \\
6\end{array}$ & $\begin{array}{c}0.002 \\
6\end{array}$ & $\begin{array}{c}0.281 \\
0\end{array}$ & $\begin{array}{c}0.001 \\
3\end{array}$ \\
\hline & ODPA & $\begin{array}{c}241.4 \\
3\end{array}$ & $\begin{array}{c}24.09 \\
46\end{array}$ & $\begin{array}{c}20.57 \\
54\end{array}$ & $\begin{array}{c}0.060 \\
0\end{array}$ & $\begin{array}{c}0.003 \\
1\end{array}$ & $\begin{array}{c}0.302 \\
8\end{array}$ & $\begin{array}{c}0.001 \\
1\end{array}$ \\
\hline & pTDPA & $\begin{array}{c}249.6 \\
0\end{array}$ & & & $\begin{array}{c}2.418 \\
2\end{array}$ & $\begin{array}{c}0.075 \\
8\end{array}$ & $\begin{array}{c}20.29 \\
70\end{array}$ & \\
\hline & mTDPA & $\begin{array}{c}248.6 \\
9\end{array}$ & & 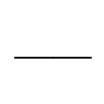 & $\begin{array}{c}4.758 \\
8\end{array}$ & $\begin{array}{c}0.277 \\
1\end{array}$ & $\begin{array}{c}44.98 \\
20\end{array}$ & \\
\hline
\end{tabular}




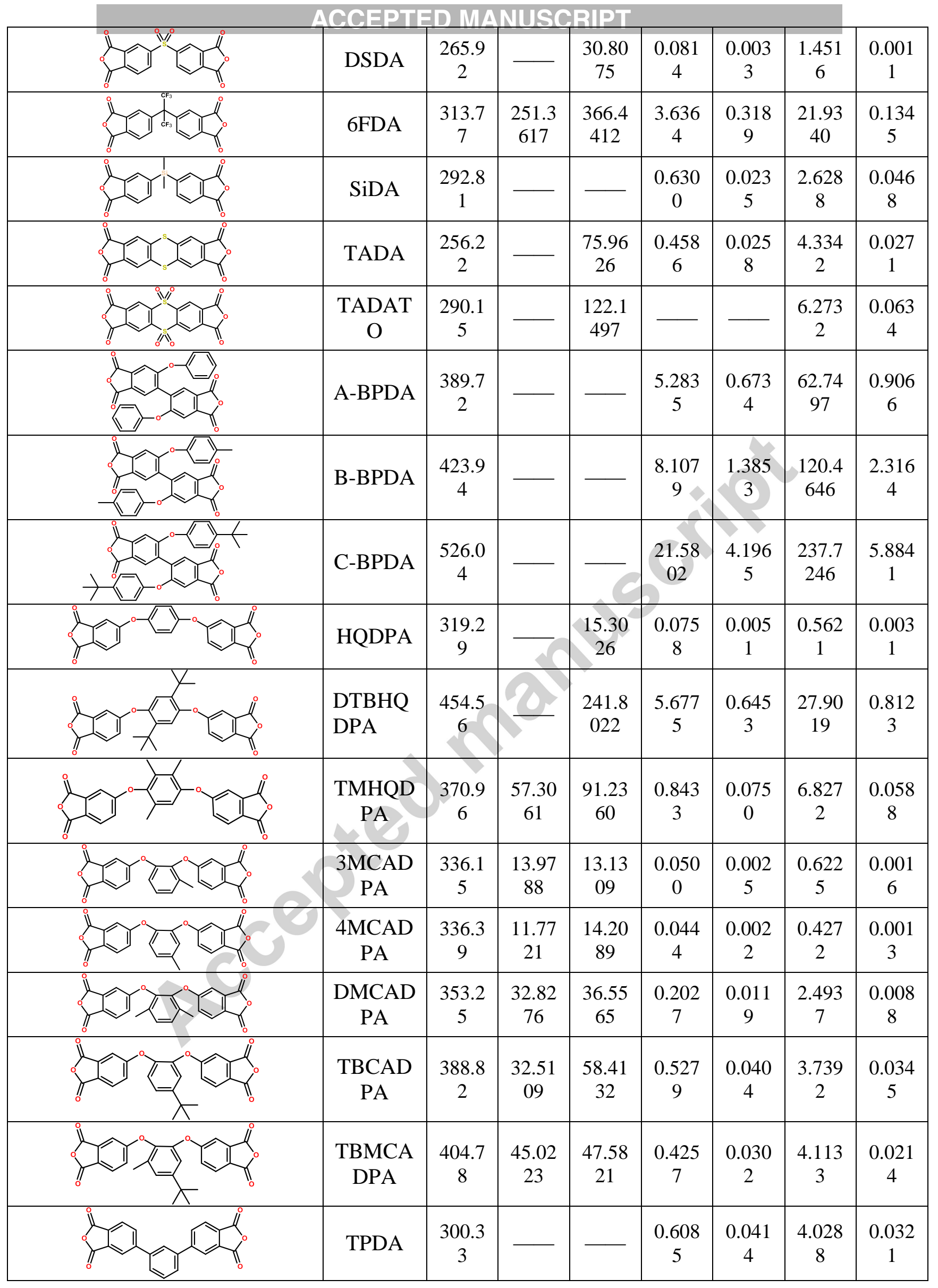




\begin{tabular}{|c|c|c|c|c|c|c|c|c|}
\hline \multicolumn{9}{|c|}{$\triangle C C C E T E D$ MANUSCBIPT } \\
\hline & BTPDA & $\begin{array}{c}317.3 \\
3\end{array}$ & $\begin{array}{c}212.1 \\
371\end{array}$ & $\begin{array}{c}10.90 \\
51\end{array}$ & $\begin{array}{c}0.681 \\
1\end{array}$ & $\begin{array}{c}0.006 \\
8\end{array}$ & $\begin{array}{c}32.79 \\
53\end{array}$ & $\begin{array}{c}0.556 \\
9\end{array}$ \\
\hline & PTPDA & $\begin{array}{c}416.3 \\
1\end{array}$ & $\begin{array}{c}122.9 \\
389\end{array}$ & - & $\begin{array}{c}3.429 \\
7\end{array}$ & $\begin{array}{c}0.476 \\
8\end{array}$ & $\begin{array}{c}26.90 \\
59\end{array}$ & $\begin{array}{c}0.630 \\
2\end{array}$ \\
\hline & BPADA & $\begin{array}{c}443.3 \\
8\end{array}$ & & $\begin{array}{c}26.13 \\
79\end{array}$ & $\begin{array}{c}0.448 \\
7\end{array}$ & $\begin{array}{l}0.040 \\
7\end{array}$ & $\begin{array}{c}3.275 \\
4\end{array}$ & $\begin{array}{c}0.040 \\
8\end{array}$ \\
\hline & $\begin{array}{c}\text { BTAPD } \\
\text { A }\end{array}$ & $\begin{array}{c}482.2 \\
1\end{array}$ & & & $\begin{array}{c}0.169 \\
7\end{array}$ & $\begin{array}{c}0.012 \\
7\end{array}$ & - & 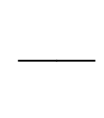 \\
\hline & DCPAN & $\begin{array}{c}317.6 \\
4\end{array}$ & & & $\begin{array}{c}0.245 \\
5\end{array}$ & $\begin{array}{c}0.034 \\
2\end{array}$ & $\begin{array}{c}3.289 \\
5\end{array}$ & $\begin{array}{c}0.079 \\
6\end{array}$ \\
\hline & $\begin{array}{c}\text { DCPAN- } \\
\mathrm{M}\end{array}$ & $\begin{array}{c}368.8 \\
7\end{array}$ & & & $\begin{array}{c}0.827 \\
1\end{array}$ & $\begin{array}{c}0.099 \\
0\end{array}$ & $\begin{array}{c}11.03 \\
55\end{array}$ & $\begin{array}{c}0.290 \\
9\end{array}$ \\
\hline & $\begin{array}{c}\text { DCPAN- } \\
\mathrm{N}\end{array}$ & $\begin{array}{c}361.1 \\
1\end{array}$ & & & $\begin{array}{c}0.523 \\
4\end{array}$ & $\begin{array}{c}0.101 \\
0\end{array}$ & $\begin{array}{c}5.666 \\
6\end{array}$ & $\begin{array}{c}0.249 \\
1\end{array}$ \\
\hline & $\begin{array}{c}\text { DCPAN- } \\
\mathrm{P}\end{array}$ & $\begin{array}{c}420.1 \\
1\end{array}$ & & & $\begin{array}{c}0.619 \\
7\end{array}$ & $\begin{array}{c}0.096 \\
2\end{array}$ & $\begin{array}{c}6.390 \\
1\end{array}$ & $\begin{array}{c}0.202 \\
3\end{array}$ \\
\hline Chemical structures of subunits & & $\begin{array}{l}\text { Molec } \\
\text { ular } \\
\text { Volum }\end{array}$ & & meabil & $\begin{array}{r}\text { y (barr } \\
\text { sub }\end{array}$ & $\begin{array}{l}\text { *) cor } \\
\text { nits }\end{array}$ & cibutior & \\
\hline Diamines & $\begin{array}{l}\text { Abbreviat } \\
\text { ion }\end{array}$ & $\begin{array}{c}\text { olum } \\
\mathrm{e}\left(\AA^{3}\right) \\
\text { of } \\
\text { subuni } \\
\text { ts }\end{array}$ & He & $\mathbf{H}_{2}$ & $\mathbf{O}_{2}$ & $\mathbf{N}_{2}$ & $\mathrm{CO}_{2}$ & $\mathrm{CH}_{4}$ \\
\hline & pPDA & 78.85 & - & $\begin{array}{c}0.008 \\
2\end{array}$ & $\begin{array}{c}3.055 \\
5\end{array}$ & $\begin{array}{c}14.42 \\
93\end{array}$ & $\begin{array}{c}5.334 \\
3\end{array}$ & $\begin{array}{c}1.000 \\
0\end{array}$ \\
\hline & mPDA & 78.61 & $\begin{array}{c}0.071 \\
0\end{array}$ & $\begin{array}{c}0.007 \\
1\end{array}$ & $\begin{array}{c}0.834 \\
9\end{array}$ & $\begin{array}{c}1.711 \\
8\end{array}$ & $\begin{array}{c}0.587 \\
9\end{array}$ & $\begin{array}{c}0.980 \\
3\end{array}$ \\
\hline & 2,6-DAT & 96.04 & $\begin{array}{c}6.273 \\
3\end{array}$ & $\begin{array}{c}1.665 \\
5\end{array}$ & $\begin{array}{c}240.1 \\
804\end{array}$ & $\begin{array}{c}263.0 \\
960\end{array}$ & $\begin{array}{c}170.9 \\
362\end{array}$ & $\begin{array}{c}155.9 \\
783\end{array}$ \\
\hline & 2,4-DAT & 96.81 & - & $\begin{array}{c}0.455 \\
3\end{array}$ & $\begin{array}{c}75.39 \\
17\end{array}$ & $\begin{array}{c}131.4 \\
566\end{array}$ & $\begin{array}{c}222.9 \\
482\end{array}$ & $\begin{array}{c}284.9 \\
436\end{array}$ \\
\hline & pDiMPD & 113.7 & - & $\begin{array}{c}5.340 \\
5\end{array}$ & $\begin{array}{c}490.0 \\
59\end{array}$ & $\begin{array}{c}940.6 \\
82\end{array}$ & $\begin{array}{c}268.4 \\
19\end{array}$ & $\begin{array}{c}327.5 \\
35\end{array}$ \\
\hline
\end{tabular}




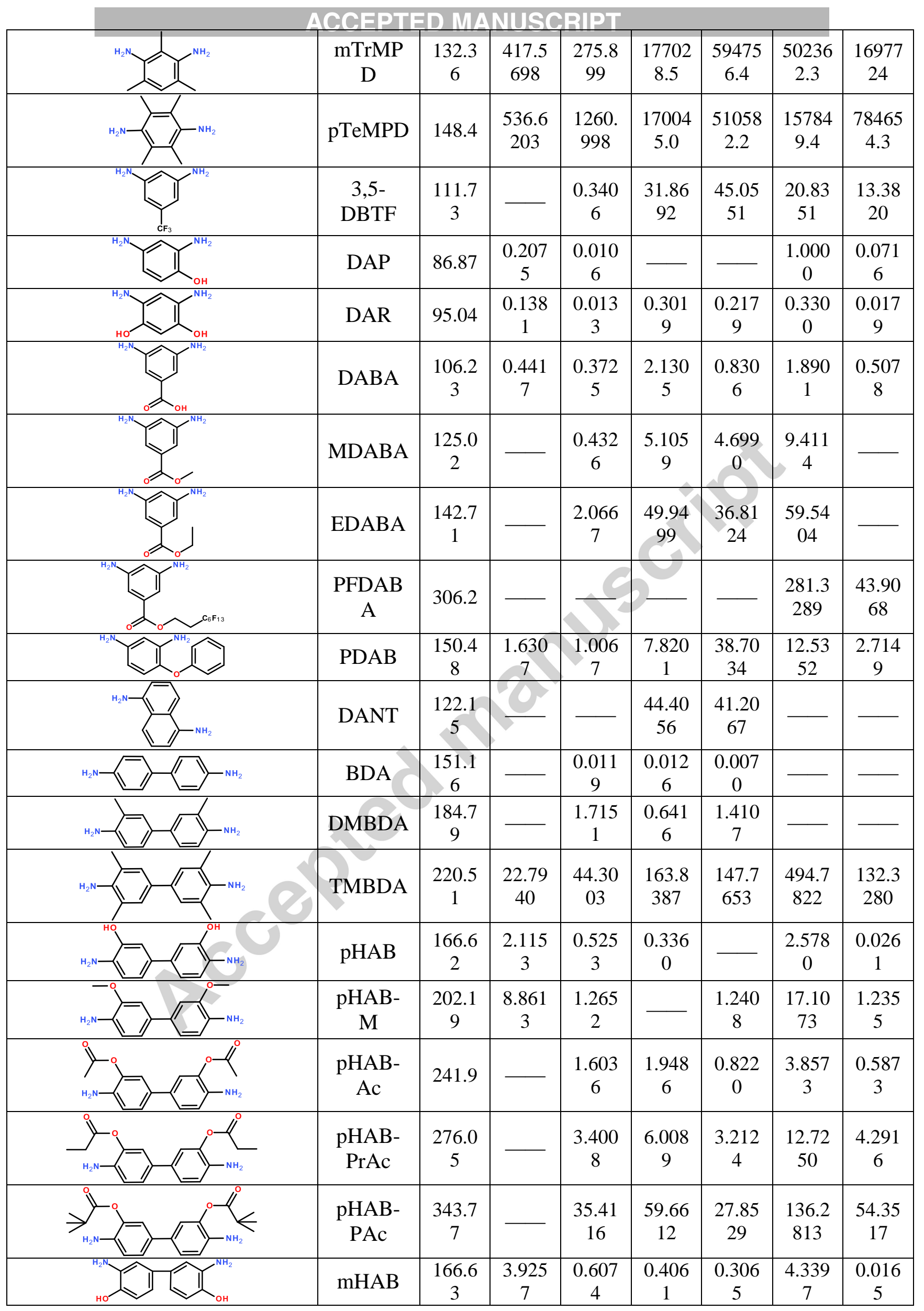




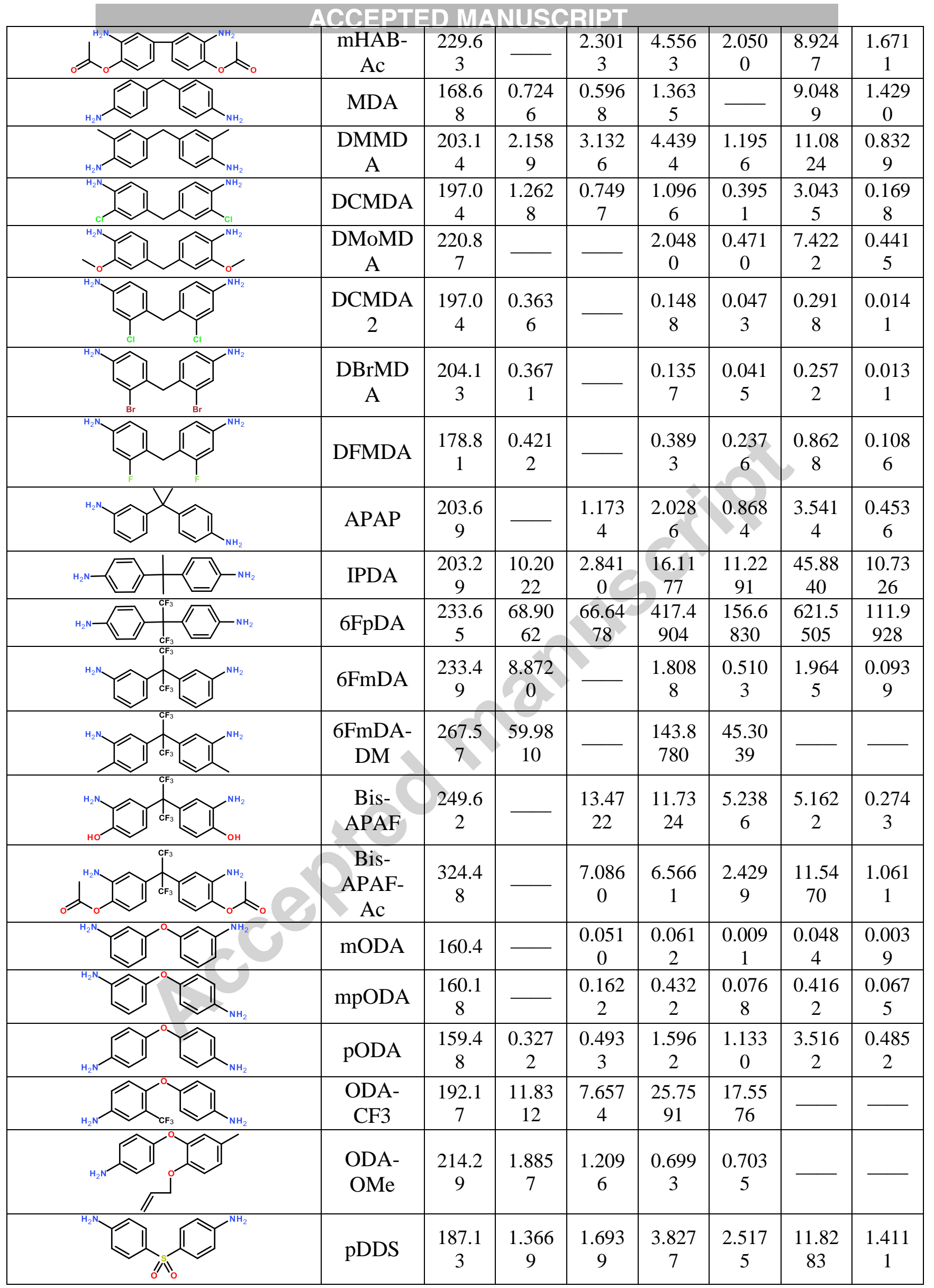




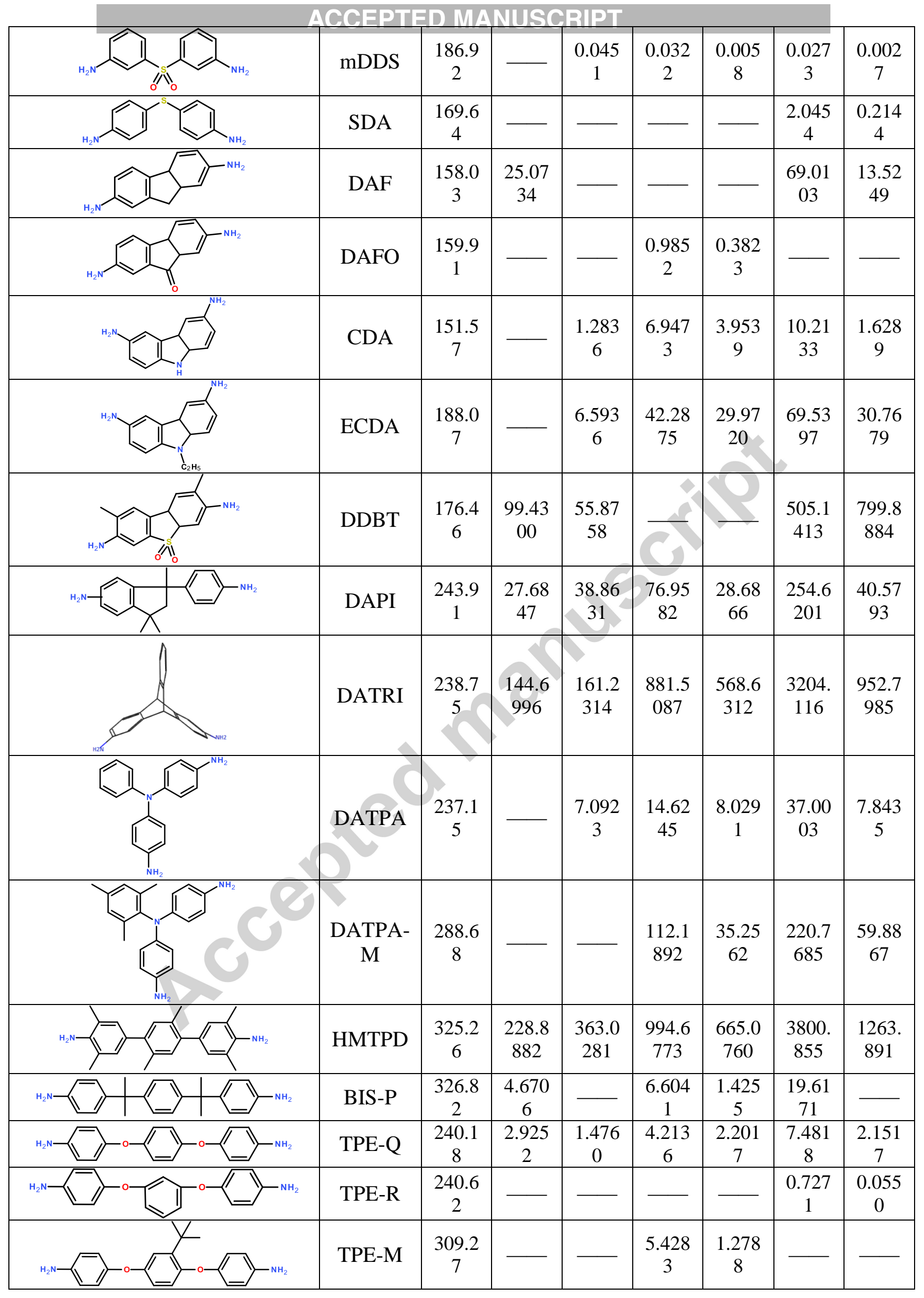




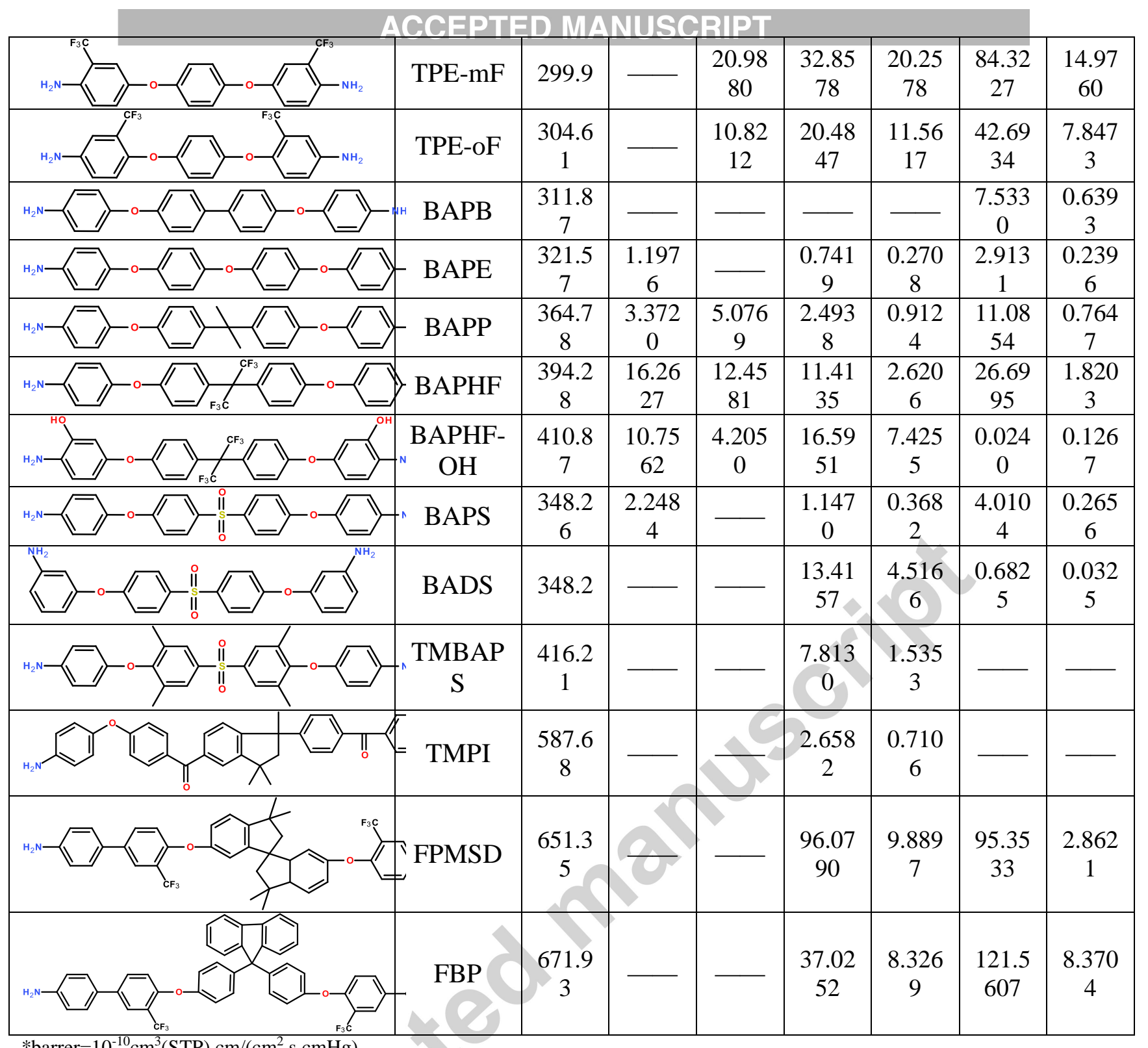

*barrer $=10^{-10} \mathrm{~cm}^{3}(\mathrm{STP}) . \mathrm{cm} /\left(\mathrm{cm}^{2} . \mathrm{s} . \mathrm{cmHg}\right)$ 
Abbreviations:

\section{Dianhydrides}

\begin{tabular}{|c|c|}
\hline PMDA & : pyromellitic dianhydride \\
\hline NTDA & : 1,4,5,8-naphthalene tetracarboxylic dianhydride \\
\hline BPDA & : 3,3',4,4'-biphenyltetracarboxylic dianhydride \\
\hline BTDA & : 3,3',4,4'-benzophenonetetracarboxylic dianhydride \\
\hline ODPA & : 4,4'-oxydiphthalic anhydride \\
\hline pTDPA & : 3,3',4,4'-thiaphthalic dianhydride \\
\hline mTDPA & : 2,2',3,3'-thiaphthalic dianhydride \\
\hline DSDA & : 3,3',4,4'-diphenylsulfone tetracarboxylic dianhydride \\
\hline 6FDA & : 4,4'-(hexafluoroisopropylidene)diphthalic anhydride \\
\hline SiDA & : bis (phthalic anhydride) dimethylsilane \\
\hline TADA & : thianthrene-2,3,7,8-tetracarboxylic dianhydride \\
\hline TADATO & : thianthrene-2,3,7,8-tetracarboxylic dianhydride-5,5,10,10-tetraoxide \\
\hline A-BPDA & : 2,2'-diphenoxy-4,4',5,5'-biphenyltetracarboxylic dianhydride \\
\hline B-BPDA & : 2,2'-di(p-methylphenoxy)-4,4',5,5'-biphenyltetracarboxylic dianhydride \\
\hline C-BPDA & : 2,2'-di (p-tert-butylphenoxy)-4,4',5,5'-biphenyltetracarboxylic dianhydride \\
\hline HQDPA & : 1,4-bis(3,4-dicarboxyphenoxy)benzene dianhydride \\
\hline DTBHQDPA & : Dianhydride $\boldsymbol{J}$ in [71] \\
\hline TMHQDPA & : Dianhydride $\boldsymbol{H}$ in [71] \\
\hline 3MCADPA & : Dianhydride $\boldsymbol{A}$ in [71] \\
\hline 4MCADPA & : Dianhydride $\boldsymbol{B}$ in [71] \\
\hline DMCADPA & : Dianhydride $\boldsymbol{C}$ in [71] \\
\hline TBCADPA & : Dianhydride $\boldsymbol{D}$ in [71] \\
\hline TBMCADPA & : Dianhydride $\boldsymbol{E}$ in [71] \\
\hline TPDA & : 3,4,3',4'”-m-terphenyltetracarboxylicdianhydride \\
\hline BTPDA & : 5'-t-butyl-m-terphenyl-3,4,3', 4 ''-tetracarboxylic acid dianhydride \\
\hline PTPDA & : 5'-t-butyl-2'-pivaloylimino-3,4,3', 4 ''-m-terphenyltetracarboxylic dianhydride \\
\hline BPADA & : 4,4'-(4,4'-isopropylidenediphenoxy)bis(phthalic anhydride) \\
\hline BTAPDA & : 2,2'-bis(p-trimellitoxyphenyl) propane dianhydride \\
\hline DCPAN & : n,n-bis (3,4-dicarboxyphenyl)aniline dianhydride \\
\hline DCPAN-M & : n,n-bis(3,4-dicarboxyphenyl)-2,4,6-trimethylaniline dianhydride \\
\hline DCPAN-N & : n,n-bis(3,4-dicarboxyphenyl)-1-aminonaphthalene dianhydride \\
\hline DCPAN|-P & : n,n-bis(3,4-dicarboxyphenyl)-1-aminopyrene dianhydride \\
\hline
\end{tabular}

Diamines:

\begin{tabular}{|c|c|}
\hline pPDA & : 1,4-phenylenediamine \\
\hline mPDA & : 1,3-phenylenediamine \\
\hline 2,6-DAT & : 2-methyl-1,3-phenylenedimine \\
\hline 2,4-DAT & : 2,4-diaminotoluene \\
\hline pDiMPD & : 2,5-dimethyl-1,4-phenylenediamine \\
\hline mTrMPD & : 2,4,6-trimethyl-1,3-phenylene- diamine \\
\hline pTeMPD & : 2,3,5,6-tetramethyl-1,4-phenylenediamine \\
\hline $3,5-\mathrm{DBTF}$ & : 3,5-diaminobenzotriflouride \\
\hline DAP & : 2,4-diaminophenol di hydroxyl \\
\hline DAR & : 4,6-diaminoresorcinol di hydroxyl \\
\hline DABA & : 3,5-diaminobenzoic acid \\
\hline MDABA & : methyl 3,5-diaminobenzoate \\
\hline EDABA & : ethyl 3,5-dlaminobenzoate \\
\hline PFDABA & : 2-(perfluorohexyl)ethyl-3, 5-diamino benzoate \\
\hline PDAB & : 1-phenoxy-2,4-diaminobenzene \\
\hline DANT & : 1,5-naphthalene \\
\hline BDA & : benzidine \\
\hline DMBDA & : 3,3'-dimethylbenzidine \\
\hline TMBDA & : 3,3',4,4'-tetramethyl- benzidine \\
\hline pHAB & : 3,3'-dihydroxybenzidine \\
\hline pHAB-M & : 3,3'-dimethoxybenzidine \\
\hline pHAB-Ac & : 3,3'-dihydroxy-4,4'-diamino-biphenyl-acetate \\
\hline pHAB-PrAc & : 3,3'-dihydroxy-4,4'-diamino-biphenyl- propanoa \\
\hline
\end{tabular}




\begin{tabular}{|c|c|}
\hline \multirow{2}{*}{\multicolumn{2}{|c|}{ pHAB-PAc $\quad: 3,3$ '-dihydroxy-4,4'-diamino-biphenyl-pivalate }} \\
\hline & \\
\hline mHAB & : 3,3'-diamino-4,4'-dihydroxybiphenyl \\
\hline mHAB-Ac & : 3,3'-diamino-4,4'-dihydroxybiphenyl-acetate \\
\hline MDA & : methylenedianiline \\
\hline DMMDA & : 4,4'-methylene-bis(2-methylaniline) \\
\hline TMMDA & : tetramethylmethylene dianiline \\
\hline DCMDA & : 4,4'-methylene bis(2-chloroaniline) \\
\hline DMoMDA & : 3,3'-dimethoxy-4,4'- methylenedianiline \\
\hline DCMDA2 & : 4,4'-methylene bis(3-chloroaniline) \\
\hline DBrMDA & : di brominated 4,4'-methylenedianiline \\
\hline DFMDA & : 4,4'-methylene bis(3-flouroaniline) \\
\hline APAP & : 2-(3-amino-(4-phenyl)-2-aminophenyl)propane \\
\hline IPDA & : isopropylidenedianiline \\
\hline 6FpDA & : 4,4'-(hexaflouroisopropylidene)-dianiline \\
\hline 6FmDA & : 2,2'-(hexaflouroisopropylidene)-dianiline \\
\hline 6FmDA-DM & : 2,2-bis-(3-amino-4-methylphenyl)hexafluoro-propane \\
\hline Bis-APAF & : 2,2'-bis(3-amino-4-hydroxyphenyl)-hexafluoropropane \\
\hline Bis-APAF-Ac & : 2,2'-bis(3-amino-4-hydroxyphenyl)-hexafluoropropane-acetate \\
\hline mODA & : 3,3'-oxydianiline \\
\hline mpODA & : 3,4'-oxydianiline \\
\hline pODA & : 4,4'-oxydianiline \\
\hline ODA-CF3 & : 2-trifluoromethyl-4,4'-diaminodiphenyl ether \\
\hline ODA-OMe & : 2-methoxy-5,4'-diaminodiphenyl ether \\
\hline pDDS & : 4,4'-Diaminodiphenyl sulfone \\
\hline $\mathrm{mDDS}$ & : 3,3'-Diaminodiphenyl sulfone \\
\hline SDA & : 4,4'-diaminodiphenylsulfide \\
\hline DAF & : 2,7-fluorenediamine \\
\hline DAFO & : 2,7-diaminofluorenone \\
\hline CDA & : 3,6-diaminocarbazole \\
\hline ECDA & : n-ethyl-3,6-diaminocarbazole \\
\hline DDBT & : 3,7-diamino-2,8-dimethyldibenzothiophene sulfone \\
\hline DAPI & : 5(6)-amino-1-(4' aminophenyl)-1,3,-trimethylindane \\
\hline DATRI & : 2,6-diaminotriptycene \\
\hline DATPA & : 4,4'-diaminotriphenylamine \\
\hline DATPA-M & : 4,4'-diamino-2', 4 ,',6"'-trimethyltriphenylamine \\
\hline HMTPD & : 1,3,3',3', 5,5',6'-hexamethyl-(1,1',1''-triphenyl)-4,4'-diamine \\
\hline BIS-P & : 4,4'-[(1,4-phenylene)dipropane-2,2-diyl]dianiline \\
\hline TPE-Q & : 1,4-bis(4-amino-phenoxy)benzene \\
\hline TPE-R & : 1,4-bis(3-amino-phenoxy)benzene \\
\hline TPE-M & : 1,4-bis(4-aminophenoxy)2-tert-butylbenzene \\
\hline TPE-mF & : 1,4-bis(4-amino-3-trifluoromethylphenoxy)benzene \\
\hline TPE-oF & : 2,3-bis(4-amino-3-trifluoromethylphenoxy)benzene \\
\hline BAPB & : 4,4'-bis (4-aminophenoxy) biphenyl \\
\hline BAPE & : bis[4-(4-aminophenoxy)phenyl]ether \\
\hline BAPP & : 2,2-bis [4-(4-aminophenoxy)phenyl] propane \\
\hline BAPHF & : 2,2-bis(4-(4-aminophenoxy) phenyl) hexafluoropropane \\
\hline BAPHF-OH & : 2,2-bis(4-(4-amino-3-hydroxyphenoxy)phenyl)- hexafluoropropane) \\
\hline BAPS & : 2,2-bis [4-(4-aminophenoxy) phenyl] sulfone \\
\hline BADS & : 4,4'- bis(3-aminophenoxy)diphenyl sulfone \\
\hline TMBAPS & : 3,3',5,5'-tetramethyl-bis[4-(4-aminophenoxy)phenyl]sulfone \\
\hline TMPI & : in ref. [72] \\
\hline FPMSD & : 6,6-bis-[2-trifluoromethyl 4-(4-aminophenyl)phenoxy]-3,3,3,3-tetramethyl-1,1-spirobiindane \\
\hline FBP & : 4,4'-bis-((2'-trifluoromethyl-4'-(4''-aminophenyl) phenoxy)-9-fluorenylidene \\
\hline
\end{tabular}




\section{ACKNOWLEDGEMENTS}

\section{ACCEPTED MANUSCRIPT}

We acknowledge funding from the Nanyang Technological University iFood Research Grant, and the Singapore Ministry of Education Academic Research Funds Tier 2 (MOE2014-T2-2-074; ARC16/15) and Tier 1 (2015-T1-001-023; RG7/15). The Singapore Membrane Technology Center (SMTC) acknowledges support from the Singapore Economic Development Board (EDB).

\section{REFERENCES}

[1] L. M. Robeson, C. D. Smith, M. Langsam, A group contribution approach to predict permeability and permselectivity of aromatic polymers, Journal of Membrane Science 132 (1997) 33-54.

[2] Y. Yampolskii, I. Pinnau, B. D. Freeman, Materials science of membranes for gas and vapor separation, John Wiley \& Sons Ltd, England, $1^{\text {st }}$ Ed. 2006.

[3] E. Drioli, L. Giorno, Membrane Operations, Innovative Separations and Transformations, Wiley-VCH Verlag GmbH \& Co. KGaA, Weinheim, Germany, 2009.

[4] R. W. Baker, Membrane Technology and Applications, John Wiley \& Sons Ltd, England, $2^{\text {nd }}$ Ed. 2004.

[5] W. J. Koros, R. Mahajan, Pushing the limits on possibilities for large scale gas separation: which strategies?, Journal of Membrane Science 175 (2000) 181-196.

[6] M. Ulbricht, Advanced functional polymer membranes, Polymer 47 (2006) 2217-2262.

[7] D. F. Sanders, Z. P. Smith, R. Guo, L. M. Robeson, J. E. McGrath, D. R. Paul, B. D. Freeman, Energy-efficient polymeric gas separation membranes for a sustainable future: A review, Polymer 54 (2013) 4729-4761.

[8] Y. Xiao, B. T. Low, S. S. Hosseini, T. S. Chung, D. R. Paul, The strategies of molecular architecture and modification of polyimide-based membranes for $\mathrm{CO}_{2}$ removal from natural gas-A review, Progress in Polymer Science 34 (2009) 561-580.

[9] D. J. Liaw, K. L. Wang, Y. C. Huang, K. R. Lee, J. Y. Lai, C. S. Ha, Advanced polyimide materials: Syntheses, physical properties and applications, Progress in Polymer Science 37 (2012) 907-974.

[10] L. Wang, Y. Cao, M. Zhou, S. J. Zhou, Q. Yuan, Novel copolyimide membranes for gas separation, Journal of Membrane Science 305 (2007) 338-346. 
[11] L. Wang, Y. Cao, M. Zhou, X. Ding, Q. Liu, Q. Yuan, The gas permeation properties of 6FDA-2, 4, 6-trimethyl-1, 3-phenylenediamine (TMPDA)/1, 3-phenylenediamine (mPDA) copolyimides, Polymer Bulletin 60 (2008) 137-147.

[12] M. Niwa, S. Nagaoka, H. Kawakami, Preparation of novel fluorinated block copolyimide membranes for gas separation, Journal of Applied Polymer Science 100 (2006) 2436-2442.

[13] K. Tanaka, M. Okano, H. Toshino, H. Kita, K. I. Okamoto, Effect of methyl substituents on permeability and permselectivity of gases in polyimides prepared from methyl-substituted phenylenediamines, Journal of Polymer Science: Part B: Polymer Physics 30 (1992) 907-914.

[14] Y. Liu, R. Wang, T. S. Chung, Chemical cross-linking modification of polyimide membranes for gas separation, Journal of Membrane Science 189 (2001) 231-239.

[15] J. Y. Park, D. R. Paul, Correlation and prediction of gas permeability in glassy polymer membrane materials via a modified free volume based group contribution method, Journal of Membrane Science 125 (1997) 23-39.

[16] A. Y. Alentiev, K. A. Loza, Y. P. Yampolskii, Development of the methods for prediction of gas permeation parameters of glassy polymers: polyimides as alternating co-polymers, Journal of Membrane Science 167 (2000) 91-106.

[17] S. Velioglu, S. B. Tantekin-Ersolmaz, Prediction of gas permeability coefficients of copolyimides by group contribution methods, Journal of Membrane Science 480 (2015) 47-63.

[18] D. V. Laciak, L. M. Robeson, C. D. Smith, 1999. Group contribution modeling of gas transport in polymeric membranes, in: B.D. Freeman, I. Pinnau (Eds.), Polymer membranes for gas and vapor separation, ACS Symposium Series 733, American Chemical Society, Washington, DC, p. 151.

[19] V. Ryzhikh, D. Tsarev A. Alentiev Y. Yampolskii, A novel method for predictions of the gas permeation parameters of polymers on the basis of their chemical structure, Journal of Membrane Science 487 (2015) 189-198.

[20] M. Salame, Prediction of gas barrier properties of high polymers, Polymer Engineering and Science 26 (1986) 1543-1546.

[21] Membrane Society of Australasia, Polymer Gas Separation Membranes, https://www.membrane-australasia.org/polymer-gas-separation-membranes/. 
[22] Y. Yampolskii, S. Shishatskii, A. Alentiev, K. Loza, Correlations with and prediction of activation energies of gas permeation and diffusion in glassy polymers, Journal of Membrane Science 148 (1998) 59-69.

[23] S. Plimpton, Fast parallel algorithms for short-range molecular dynamics, Journal of Computational Physics 117 (1995) 1-19, http://lammps.sandia.gov/.

[24] P. Dauber-Osguthorpe, V. A. Roberts, D. J. Osguthorpe, J. Wolff, M. Genest, A. T. Hagler, Structure and energetics of ligand binding to proteins: E. coli dihydrofolate reductasetrimethoprim, a drug-receptor system, Proteins: Structure, Function and Genetics 4 (1988) 3147.

[25] Dassault Systèmes BIOVIA, Discovery Studio Modeling Environment, Release 2017, San Diego: Dassault Systèmes, 2016.

[26] A. Bondi, Physical Properties of Molecular Crystals, Liquids and Glasses, Wiley, New York, 1968.

[27] L. M. Robeson, Correlation of separation factor versus permeability for polymeric membranes, Journal of Membrane Science 62 (1991) 165-185.

[28] L. M. Robeson, The upper bound revisited, Journal of Membrane Science 320 (2008) 390-400.

[29] K. Tanaka, M. Okano, H. Toshino, H. Kita, K. Okamoto, Effect of methyl substituents on permeability and permselectivity of gases in polyimides prepared from methyl-substituted phenylenediamines, Journal of Polymer Science: Part B: Polymer Physics 30 (1992) 907-914.

[30] L. Wang, Y. Cao, M. Zhou, X. Ding, Q. Liu, Q. Yuan, The gas permeation properties of 6FDA-2, 4, 6-trimethyl-1, 3-phenylenediamine (TMPDA)/1, 3-phenylenediamine (mPDA) copolyimides, Polymer Bulletin 60 (2008) 137-147.

[31] J. H. Kim, W. J. Koros, D. R. Paul, Effects of CO2 exposure and physical aging on the gas permeability of thin 6FDA-based polyimide membranes Part 1. Without crosslinking, Journal of Membrane Science 282 (2006) 21-31.

[32] L. Wang, Y. Cao, M. Zhou, S. J. Zhou, Q. Yuan, Novel copolyimide membranes for gas separation, Journal of Membrane Science 305 (2007) 338-346.

[33] S. Miyata, S. Sato, K. Nagai, T. Nakagawa, K. Kudo, Relationship between gas transport properties and fractional free volume determined from dielectric constant in polyimide films containing the hexafluoroisopropylidene group, Journal of Applied Polymer Science 107 (2008) 3933-3944. 
[34] W. Qiu, L. Xu, C. C. Chen, D. R. Paul, W. J. Koros, Gas separation performance of 6FDAbased polyimides with different chemical structures, Polymer 54 (2013) 6226-6235.

[35] R. L. Burns, W. J. Koros, Structure-property relationships for poly(pyrrolone-imide) gas separation membranes, Macromolecules 36 (2003) 2374-2381.

[36] M. Niwa, S. Nagaoka, H. Kawakami, Preparation of novel fluorinated block copolyimide membranes for gas separation, Journal of Applied Polymer Science 100 (2006) 2436-2442.

[37] Y. Liu, C. Pan, M. Ding, J. Xu, Gas permeability and permselectivity of polyimides prepared from phenylenediamines with methyl substitution at the ortho position, Polym Int 48 (1999) 832-836.

[38] S. K. Sen, S. Banerjee, Spiro-biindane containing fluorinated poly(ether imide)s: Synthesis, characterization and gas separation properties, Journal of Membrane Science 365 (2010) 329340.

[39] K. Tanaka, H. Kita, M. Okano, K. Okamoto, Permeability and permselectivity of gases in fluorinated and non-fluorinated polyimides, Polymer 33 (1992) 585-592.

[40] Y. Hirayama, T. Yoshinaga, Y. Kusuki, K. Ninomiya, T. Sakakibara, T. Tamari, Relation of gas permeability with structure of aromatic polyimides I, Journal of Membrane Science 111 (1996) 169-182.

[41] Y. Li, X. Wang, M. Ding, J. Xu, Effects of molecular structure on the permeability and permseledivity of aromatic polyimides, Journal of Applied Polymer Science 61 (1996) 741748.

[42] Z. Wenle, L. Fengcai, Silicon-containing polyimides for gas separation, Polymer 35 (1994) 590-593.

[43] S. S. Chan, T. S. Chung, Y. Liu, R. Wang, Gas and hydrocarbon (C2 and C3) transport properties of co-polyimides synthesized from 6FDA and 1,5-NDA (naphthalene)/Durene diamines, Journal of Membrane Science 218 (2003) 235-245.

[44] C. Staudt-Bickel, Cross-linked copolyimide membranes for the separation of gaseous and liquid mixtures, Soft materials 1 (2003) 277-293.

[45] W. Lin, R. H. Vora, T. S. Chung, Gas transport properties of 6FDA-durene/1,4phenylenediamine (pPDA) copolyimides, Journal of Polymer Science: Part B: Polymer Physics 38 (2000) 2703-2713. 
[46] K. Matsumoto, P. Xu, Gas permeation of aromatic polyimides. II. Influence of chemical structure, Journal of Membrane Science 81 (1993) 23-30.

[47] Y. C. Wang, S. H. Huang, C. C. Hu, C. L. Li, K. R. Lee, D. J. Liaw, J. Y. Lai, Sorption and transport properties of gases in aromatic polyimide membranes, Journal of Membrane Science 248 (2005) 15-25.

[48] K. Tanaka, Y. Osada, H. Kita, K. Okamoto, Gas permeability and permselectivity of polyimides with large aromatic rings, Journal of Polymer Science: Part B Polymer Physics 33 (1995) 1907-1915.

[49] M. Al-Masri, D. Fritsch, H. R. Kricheldorf, New polyimides for gas separation. 2. Polyimides derived from substituted catechol bis(etherphthalic anhydride)s, Macromolecules 33 (2000) $7127-7135$.

[50] A. Shimazu, T. Miyazaki, M. Maeda, K. Ikeda, Relationships between the Chemical Structures and the Solubility, Diffusivity, and Permselectivity of Propylene and Propane in 6FDA-Based Polyimides Journal of Polymer Science: Part B: Polymer Physics 38 (2000) 2525-2536.

[51] S. Kim, K. T. Woo, J. M. Lee, J. R. Quay, M. K. Murphy, Y. M. Lee, Gas sorption, diffusion, and permeation in thermally rearranged poly(benzoxazole-co-imide) membranes, Journal of Membrane Science 453 (2014) 556-565.

[52] Q. Liu, D. R. Paul, B. D. Freeman, Gas permeation and mechanical properties of thermally rearranged (TR) copolyimides, Polymer 82 (2016) 378-391.

[53] Z. P. Smith, G. Hernández, K. L.Gleason, A. Anand, C. M. Doherty, K. Konstas, C. Alvarez, A. J. Hill, A. E. Lozano, D. R. Paul, B. D. Freeman, Effect of polymer structure on gas transport properties of selected aromatic polyimides, polyamides and TR polymers, Journal of Membrane Science 493 (2015) 766-781.

[54] H. B. Park, C. H. Jung, Y. M. Lee, A. J. Hill, S. J. Pas, S. T. Mudie, E. Van Wagner, B. D. Freeman, D. J. Cookson, Polymers with cavities tuned for fast selective transport of small molecules and ions, Science 318 (2007) 254-258.

[55] K. L. Gleason, Z. P. Smith, Q. Liu, D. R. Paul, B. D. Freeman, Pure- and mixed- gas permeation of $\mathrm{CO}_{2}$ and $\mathrm{CH}_{4}$ in thermally rearranged polymers based on 3,3'-dihydroxy-4,4'diamino-biphenyl (HAB) and 2,2'-bis-(3,4-dicarboxyphenyl) hexafluoropropane dianhydride (6FDA), Journal of Membrane Science 475 (2015) 204-214. 
[56] T. H. Kim, W. J. Koros, G. R. Husk, K. C. O’brien, Relationship between gas separation properties and chemical structure in a series of aromatic polyimides, Journal of Membrane Science 37 (1988) 45-62.

[57] S. A. Stern, Y. Mi, H. Yamamoto, Structure / permeability relationships of polyimide membranes. Applications to the separation of gas mixtures, Journal of Polymer Science: Part B: Polymer Physics 27 (1989) 1887-1909.

[58] K. I. Okamoto, K. Tanaka, H. Kita, M. Ishida, M. Kakimoto, Y. Imai, Gas permeability and permselectivity of polyimides prepared from 4,4'-diaminotriphenylamine, Polymer Journal 24 (1992) 451-457.

[59] J. Hao, K. Tanaka, H. Kita, K. I. Okamoto, Synthesis and properties of polyimides from thianthrene-2,3,7,8-tetracarboxylic dianhydride-5,5,10,10-tetraoxide, Journal of Polymer Science: Part A: Polymer Chemistry 36 (1998) 485-494.

[60] D. R. B. Walker, W. J. Koros, Transport characterization of a polypyrrolone for gas separations, Journal of Membrane Science 55 (1991) 99-117.

[61] M. Calle, A. E. Lozano, J. G. de La Campa, J. de Abajo, Novel Aromatic Polyimides Derived from 5'-t-Butyl-2'-pivaloylimino-3,4,3', 4' '-m-terphenyltetracarboxylic Dianhydride with Potential Application on Gas Separation Processes, Macromolecules 43 (2010) 2268-2275.

[62] M. Calle, C. Garcia, A. E. Lozano, J. G. de la Campa, J. de Abajo, C. Alvarez, Local chain mobility dependence on molecular structure in polyimides with bulky side groups: Correlation with gas separation properties, Journal of Membrane Science 434 (2013) 121-129.

[63] G. Xuesong, L. Fengcai, Gas transport properties of polyimides and polypyrrolone containing ester linkage, Polymer 36 (1995) 1035-1038.

[64] B. Comesaña-Gándara, M. Calle, H. J. Jo, A. Hernández, J. G. Dela Campa, J. Abajo, A. E. Lozano, Y. M. Lee, Thermally rearranged polybenzoxazoles membranes with biphenyl moieties: Monomer isomeric effect, Journal of Membrane Science 450 (2014) 369-379.

[65] H. Borjigin, Q. Liu, W. Zhang, K. Gaines, J. S. Riffle, D. R. Paul, B. D. Freeman, J. E. McGrath, Synthesis and characterization of thermally rearranged (TR) polybenzoxazoles: Influence of isomeric structure on gas transport properties, Polymer 75 (2015) 199-210.

[66] K. Tanaka, Md. N. Islam, M. Kido, H. Kita, K. I. Okamoto, Gas permeation and separation properties of sulfonated polyimide membranes, Polymer 47 (2006) 4370-4377. 
[67] L. Yang, J. Fang, N. Meichin, K. Tanaka, H. Kita, K. Okamoto, Gas permeation properties of thianthrene-5,5,10,10-tetraoxide-containing polyimides, Polymer 42 (2001) 2021-2029.

[68] K. Matsumoto, P. Xu, T. Nishikimi, Gas permeation of aromatic polyimides. I. Relationship between gas permeabilities and dielectric constants, Journal of Membrane Science 81 (1993) $15-22$.

[69] R. Swaidan, M. Al-Saeedi, B. Ghanem, E. Litwiller, I. Pinnau, Rational Design of Intrinsically Ultramicroporous Polyimides Containing Bridgehead-Substituted Triptycene for Highly Selective and Permeable Gas Separation Membranes, Macromolecules 47 (2014) 5104-5114.

[70] S. Neyertz, Tutorial: Molecular Dynamics Simulations of Microstructure and Transport Phenomena in Glassy Polymers, Soft Materials 4(1) (2007) 15-83.

[71] M. Al-Masri, D. Fritsch, H. R. Kricheldorf, New Polyimides for Gas Separation. 2. Polyimides Derived from Substituted Catechol Bis(etherphthalic anhydride)s, Macromolecules 33 (2000) 7127-7135.

[72] Z. Qiu, G. Chen, Q. Zhang, S. Zhang, Synthesis and gas transport property of polyimide from 2,2'-disubstituted biphenyltetracarboxylic dianhydrides (BPDA), European Polymer Journal 43 (2007) 194-204. 


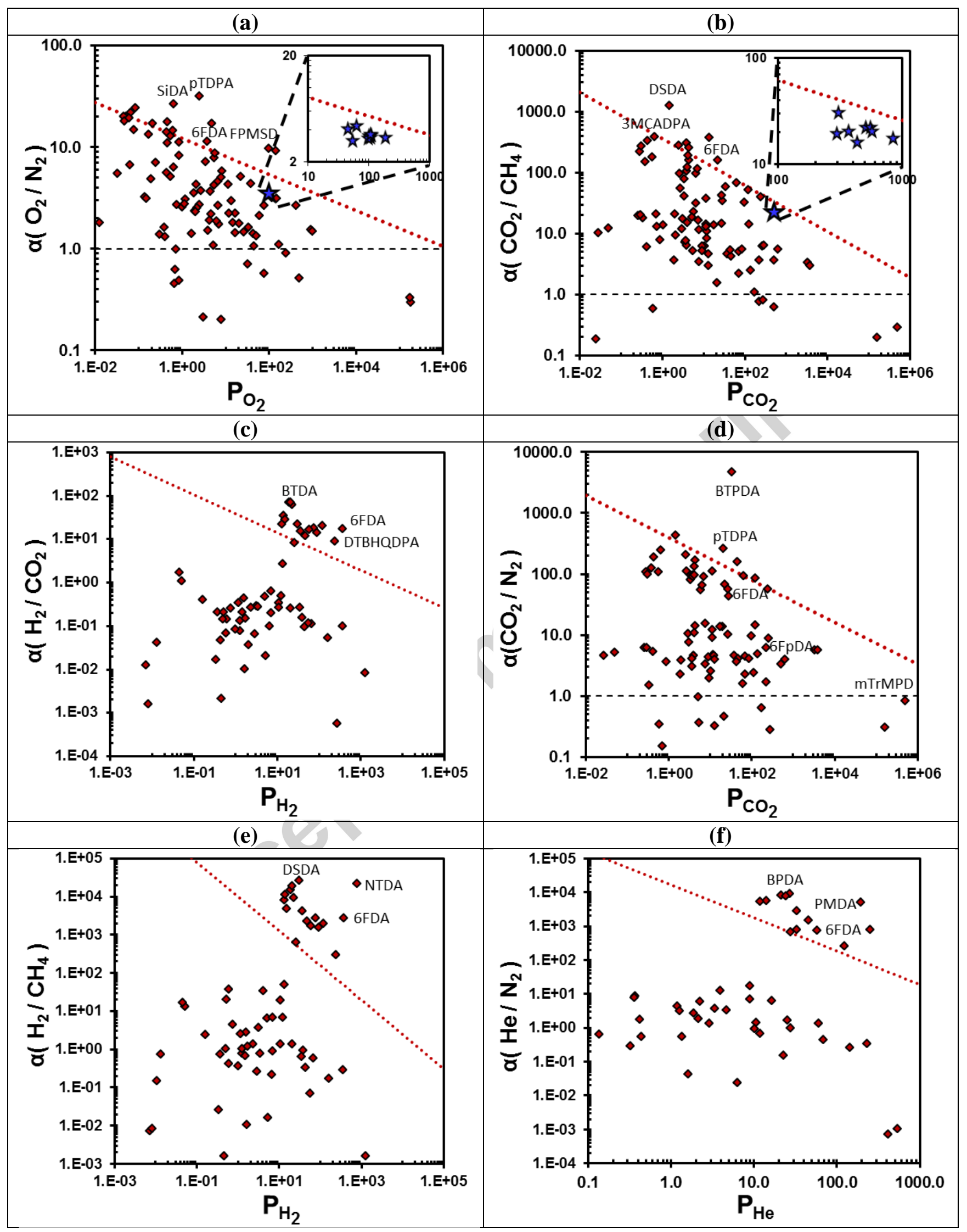


Figure A1. Predicted selectivity versus permeability diagrams for the various subunits used for the separation applications of (a) $\mathrm{O}_{2} / \mathrm{N}_{2}$, with the inset displaying the scatter of the transport properties of 6FDA-mTrMPD from nine experimental studies [29-37]; (b) $\mathrm{CO}_{2} / \mathrm{CH}_{4}$, with the inset displaying the scatter of the transport properties of 6FDA-mTrMPD from eight experimental studies [29-36]; (c) $\mathrm{H}_{2} / \mathrm{CO}_{2}$; (d) $\mathrm{CO}_{2} / \mathrm{N}_{2}$; (e) $\mathrm{H}_{2} / \mathrm{CH}_{4}$; and (f) $\mathrm{He} / \mathrm{N}_{2}$. The red dotted line represents the 2008 upper bound based on the selectivity-permeability tradeoff [28]. Note that the data points represent subunits instead of polymers.

\section{highlights}

Advances group contribution study based on molar volume contributions of subunits Database screened to identify the high-performing subunits to make up copolyimides Enhanced agreement between experimental and predicted transport properties Some gas separation properties cannot be further improved while others can Predictions indicate that polymers that exceed the trade-off bound are possible 